\title{
Use of a Functional Movement Screening Tool to Determine Injury Risk in Collegiate Acrobatics and Tumbling Athletes
}

\author{
Sara E. Spencer
}

Follow this and additional works at: https://researchrepository.wvu.edu/etd

\section{Recommended Citation}

Spencer, Sara E., "Use of a Functional Movement Screening Tool to Determine Injury Risk in Collegiate Acrobatics and Tumbling Athletes" (2016). Graduate Theses, Dissertations, and Problem Reports. 6701. https://researchrepository.wvu.edu/etd/6701

This Thesis is protected by copyright and/or related rights. It has been brought to you by the The Research Repository @ WVU with permission from the rights-holder(s). You are free to use this Thesis in any way that is permitted by the copyright and related rights legislation that applies to your use. For other uses you must obtain permission from the rights-holder(s) directly, unless additional rights are indicated by a Creative Commons license in the record and/ or on the work itself. This Thesis has been accepted for inclusion in WVU Graduate Theses, Dissertations, and Problem Reports collection by an authorized administrator of The Research Repository @ WVU. For more information, please contact researchrepository@mail.wvu.edu. 
Use of a Functional Movement Screening Tool to Determine Injury Risk in Collegiate Acrobatics and Tumbling Athletes

Sara E Spencer, ATC

Thesis submitted to the College of Physical Activity and Sports Sciences

At West Virginia University

In partial fulfillment-of the requirements

For the degree of

\author{
Masters of Science \\ In \\ Athletic Training \\ Michelle A. Sandrey, PhD, ATC, Chair \\ Jill Manners, MS, MPT, LAT, ATC, PT, COMT \\ Jean L. McCrory, PhD \\ Department of Sport Sciences
}

Morgantown, West Virginia

2016

Keywords: functional movement screen, acrobatics, tumbling, injury risk

Copyright 2016 Sara Spencer 


\begin{abstract}
Use of a Functional Movement Screening Tool to Determine Injury Risk in Collegiate Acrobatics and Tumbling Athletes
\end{abstract}

Sara E Spencer, ATC

Context: Participation in athletic teams and events can lead to injury. As the difficulty in stunts and acrobatic maneuvers increase so does the risk for injury. With this emerging sport and the skills needed to participate, it is important to identify those athletes at risk. Yet, it is unknown whether a functional screening or proprioceptive tool can be used to predict injury in this population. Objective: The purpose of this study sought to determine if compensatory movement patterns predispose acrobatics and tumbling athletes to injury, and to determine if a functional movement screening (FMS) and Lower Quarter Y Balance Test (LQ-YBT) could predict potential injury risk in the sport population. Design: This is a prospective exploratory study to screen for potential injury in the sport of acrobatics and tumbling. Setting. The testing took place in an axillary space at a DII University. Only one clinician administered the testing. Patients and Other Participants: A total of 22 participants (age 19.25yrs \pm 0.91 , height $161.97 \pm 7.03 \mathrm{~cm}$, weight $62.53 \pm 8.71 \mathrm{~kg}$ ) from an acrobatics and tumbling team were used in the study. All participants volunteered for the study, were current student-athletes at a NCAA DII institution with a physical on file and participants on a NCATA recognized Acrobatics and Tumbling team. Intervention: Scores on the FMS and LQ-YBT were calculated for NCATA Division II acrobatic and tumbling student-athletes at the start of the competitive season. The participants were asked to complete the seven movement patterns and three clearing tests of the FMS along with the LQYBT test in three directions. The participants were given a total of three practice trials for each test. Screening data was gathered over a two week period at the beginning of the season. Results. The mean FMS score and standard deviation for all subjects was $15.9 \pm 1.87$ (maximum score 21). The mean and standard deviation for all subjects were $98.36 \pm 11.63$ for the right and $99.24 \pm 12.01$ for the left. Cox Snell $\mathrm{R}^{2}$ was used to determine the percentage of the variables used to fit the model. Years of competition and total accounted injury produced a Cox Snell $\mathrm{R}^{2}$ $(0.276)$ and $\mathrm{OR}=1.451(\mathrm{CI} 95=0.980$ to 2.149$)$ for years of competition. FMS Final, LQYBT (R) and LQYBT (L): Cox Snell $\mathrm{R}^{2}$ (0.259), FMS Final not significant $(\mathrm{P}=0.36) \mathrm{OR}=1.983$ (CI95=1.045 to 3.763). FMS Cut $(\leq 14, \geq 15)$ and total accounted injury: Cox Snell $\mathrm{R}^{2}(0.342)$ and significant $(\mathrm{P}=0.028) \mathrm{OR}=28.335$ (CI95=1.429 to 561.997) for FMS Cut $(\leq 14, \geq 15)$. Conclusion: Compensatory fundamental movement patterns, increased skill and years of competition can increase the risk of injury in acrobatics and tumbling athletes. A score of 14 or less on the FMS tool paired with a higher number of previous injury resulted in a 28-fold increase in risk of injury in collegiate acrobatics and tumbling athletes.

Key Words: acrobatics, tumbling, injury risk, functional movement screen, female athlete 


\section{ACKNOWLEDGEMENTS}

I would like to express my sincere appreciation for the guidance of several individuals that have greatly impacted my education. I am thankful for the soon to be Dr. Jill Manners, my friend and mentor, from whom I have gained many insights about my education, future endeavors and this thing called life.

Bob Cable has been a supportive mentor that guided my assistantship and opened my eyes to learning that goes far beyond Athletic Training or Sports Medicine.

I would like to thank my dissertation committee for all the insight they have given me in formulating and conducting my research. Dr. Sandrey was instrumental in providing constructive feedback to strengthen this clinical study, and thoroughly inspecting and shaping my final manuscript. Dr. McCrory and Jill Manners for their help in making sure my protocol was well thought out and provided insights for how to better support the clinical practices that I refer to in this paper. I enjoyed the meetings I had with each one of you.

I would like to thank my great group of friends for their impact on my life. I would also like to thank all of my Athletic Training classmates. We shared many fun times at West Virginia, which I will always remember.

Most importantly, I would like to thank my family. While the majority of days on this adventure have been stimulating and enjoyable, I am thankful for your support during the challenging moments. To my parents, I am so grateful for your love, encouragement and support. 


\section{TABLE OF CONTENTS}

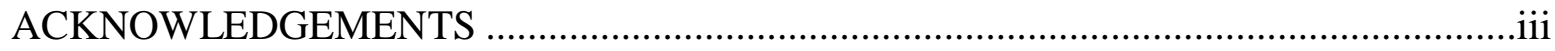

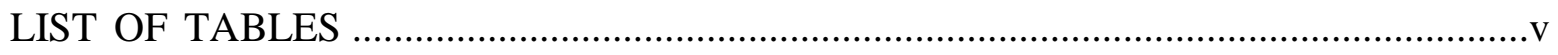

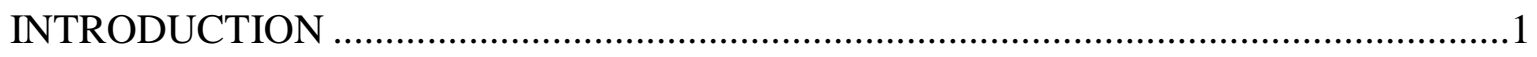

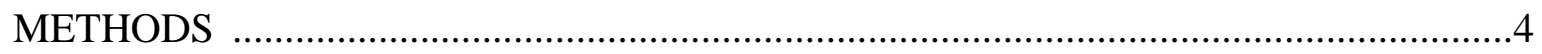

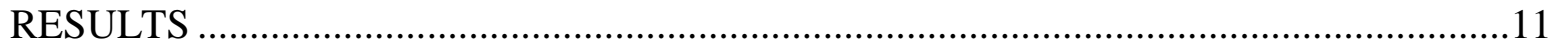

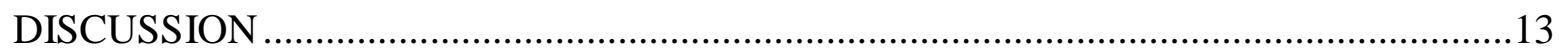

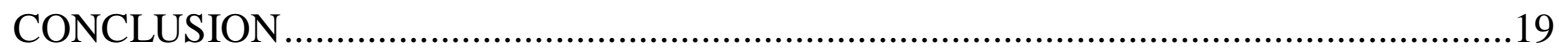

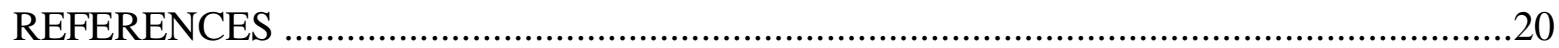

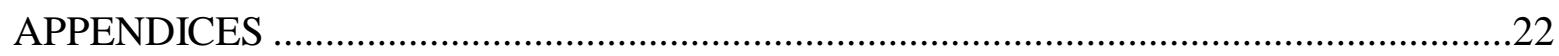

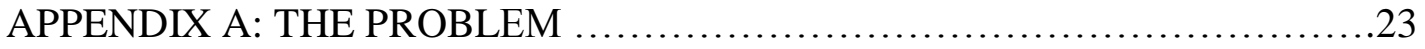

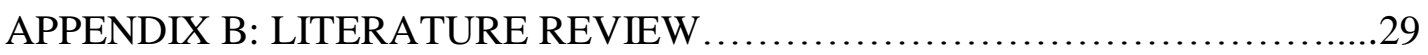

APPENDIX C: ADDITIONAL METHODS $\ldots \ldots \ldots \ldots \ldots \ldots \ldots \ldots \ldots \ldots \ldots \ldots \ldots . \ldots \ldots \ldots$

APPENDIX D: ADDITIONAL RESULTS ...................................60

APPENDIX E: RECOMMENDATION FOR FUTURE RESEARCH.............63

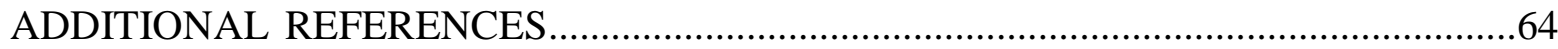




\section{LIST OF TABLES}

Table C1. Consent Information and HIPPA Form......................................................41

Table C2. Injury Self-Report Questionnaire .........................................................46

Table C3. Verbal Instructions for the Functional Movement Screen ................................49

Table C4. Functional Movement Screen Scoring Procedures ........................................53

Table C5. Functional Movement Screen Scoring Sheet ................................................57

Table C6. Lower Quarter Y Balance Test Verbal Instructions ..........................................58

Table C7. Lower Quarter Y Balance Test Scoring Sheet ............................................59

Table D1. Summary of Demographic Data ............................................................60

Table D2. Summary of FMS Scores ................................................................60

Table D3. Six Month Injury Self-Report Data.........................................................61

Table D4. Self-Reported Injuries Over 3 Year Span ....................................................62 


\section{INTRODUCTION}

There has been a significant increase in athletic participation across areas of sport for females, especially Acrobatics and Tumbling (A\&T), which is a relatively new and emerging sport at the collegiate level. The sport is described as an evolution of the different forms of cheerleading and gymnastics that involves tumbling, tosses, acrobatic lifts and pyramids.

Although the sport recruits from a variety of fields, athletes with gymnastic and cheerleading backgrounds make up the majority of team members.

Without knowledge of injury rates in A \& T, cheerleading ${ }^{2}$ provides some aspect of the potential for injury. Not only do cheerleaders lead the crowd in simple cheers but also perform a set of highly skilled maneuvers and stunts that could lead to serious injury. The majority of injuries (83-85\%) occurred during practice due to the installation of new skills and consistent repetitions. $^{3}$ The greatest risk of injury comes specifically with stunting and pyramid building $(60 \%)^{4}$ under the assumption that the base is inclined to injury due to the amount of lifts and spotting of skills. ${ }^{4}$ Injuries that resulted in a fall from height (14-20\%) ${ }^{3,5}$ occurred during a stunting maneuver. ${ }^{5}$ Ankle sprains or strains (15-24\%) were the most frequent injury sustained. ${ }^{3,5-6}$ Head injuries had a low injury rate per athletic exposure. ${ }^{3}$ Although high school cheerleaders accounted for the majority of concussions, their collegiate counterparts had more significant and catastrophic injuries.

As can be seen from cheerleading injuries, the potential for injury in A \& T could also be evident despite the lack of actual epidemiology studies. Because of a lack of reported research, there must be a way to detect actual deficiencies that may be helpful to the clinician. Thus, it is necessary to screen these athletes in hopes to find deficiencies in athletic movements.

Epidemiology studies have indicated that there are injuries in gymnastics and cheer that can 
be comparable to A\&T. However, the true mechanism of injury remains unknown. A functional screening and balance tool that incorporates athletic movements that closely resemble those that occur in A\&T will help to identify athletes at risk for injury. The majority of injuries that occur are acute in nature and happen most often during stunts and falls. ${ }^{4}$ Bases and spotters who have deficient motion can in turn increase the risk of those athletes at the top of stunts. ${ }^{4-5}$ Bases can be injured while altering movement to stay in contact with a top. Due to this lack of movement or alteration to avoid deduction, a shifting of position can lead to injuries in the low back, knee and ankle. Tops who lack proper motion and dismount from stunts improperly or fall out can increase the risk of those trying to catch them. Tops, who closely resemble flyers, on the other hand may end up with more catastrophic injuries due to the level of stunt or significant fall from height. Other musculoskeletal injuries closely related to tops predominantly involve the glenohumeral joint. Identification of all athletes who lack proper movement patterns can decrease the risk of injury though broken stunts leading to falls from a height.

Function is a common term used in clinical practice, however there is no functional evaluation standard by which to classify the term. ${ }^{8-9}$ Over the last two decades, sport rehabilitation as a profession has steered away from the traditional, isolated assessment toward an integrated, functional, movement-based approach. ${ }^{9}$ Throughout rehabilitation the clinician must realize that patient preparation to activity needs to include the screening of fundamental movement. Fitness programs and plans cannot improve an athlete if the weaknesses in fundamental movement are not identified. Two screening tools that have shown promise to evaluate functional movement are the Functional Movement Screen (FMS) and the Lower Quarter Y Balance Test (LQYBT). The FMS was designed to observe possible insufficiencies and deficits in an athlete's fundamental movement pattern. Several sports have utilized the FMS, with one study on football athletes 
indicating that previous musculoskeletal injury was associated with a lower total FMS score. ${ }^{10}$ The lower quarter Y balance test is a dynamic tool to access proprioception and balance.

Proprioception is the ability to sense limb and body position in space, which provides the athlete with a self-assessment of extremity position and movement throughout participation. The ability to maintain a stable base of support throughout static and dynamic activities is an important component of movement during sport participation. Because sport activities are rarely static in nature, the dynamic component of proprioception is extremely important. Normative values for the FMS and LQYBT have been established in specific populations, however, none that are specific to the population in question.

As A\&T continues to grow and increase in difficulty, the use of tracking and reporting injuries should follow. Currently, because of a lack of reported research, there must be a way to detect actual deficiencies that may be helpful to the clinician. Thus, it is necessary to screen these athletes in hopes of finding deficiencies in athletic movements. One way to help decrease injury is to identify those that are at risk. A functional screening and balance tool that incorporates athletic movements that closely resemble those that occur in A\&T will help to identify those athletes at risk for injury. Unfortunately there is no specific screening tool that evaluates the A\&T athlete, however, two that show promise are the FMS and the LQYBT. The FMS was designed to observe possible insufficiencies and deficits in an athlete's fundamental movement pattern. On the other hand, the LQYBT is a dynamic tool to observe proprioception and balance. As movement and balance are important to the A\&T athlete the potential to use the two as a screening tool exists. Therefore, the purpose of this study is to determine if compensatory movement patterns predispose A\&T athletes to injury, and to determine if a functional movement screen and lower quarter $\mathrm{Y}$ balance test could be used to predict injury risk in this sport population. 


\section{METHODS}

This study is a prospective exploratory screening study to determine injury risk in a Division II acrobatics and tumbling team. Subjects were tested within two weeks to the start of the competitive season. The Functional Movement Screen (FMS) was used to detect compensation patterns and deficits in movement. The Lower Quarter Y Balance Test (LQYBT) was used as a dynamic test of balance and proprioception.

Subjects

A total of twenty-seven female student-athletes participating in women's collegiate acrobatics and tumbling through the NCATA at an NCAA Division II institution during the 2016 season were recruited for this study. An informed consent (Table C1) was given to each consenting participant before the start of the study. A questionnaire (Table C2) was given to each subject too which included demographic information, skill level, and injury history to determine eligibility for the study. Inclusion criterion for this study included females 18-24 years old who had not sustained an injury (upper or lower extremity, trunk or back) within the past 15 days that prohibited full participation in regular season practice and/or conditioning programs. Exclusion criterion included an injury to the upper or lower extremity, trunk or back sustained within 15 days preceding testing that excluded the athlete from participation in practice, conditioning programs and/or competition, or recent surgical interventions that limited the athlete's participation in sport due to physician-imposed restriction. Subjects must complete both testing sessions (1 FMS, 1 LQ-YBT) in order for the results to be used in this study. The Office of Research Compliance at the institution approved the study.

Procedures

Those subjects who met all inclusion criteria were invited to participate in the study. Prior to the testing period, times were established for subjects to meet with the researcher once within a 
two week period to complete the FMS and LQYBT; approximately one 45 minute session. The participants were permitted to engage in normal daily routines without limitations. Participants were allowed to wear self-selected athletic shoes and athletic clothes for the FMS, while shoes and socks were be removed for the LQYBT. The FMS and LQYBT tools were performed in the athletic training room and auxiliary space at a Mid-Atlantic University to serve as an environmental control. Due to the amount of balance and proprioception needed to support athletes in stunts and pyramids the LQYBT was used in conjunction with the FMS in order to provide another screening tool. Administration and supervision of all testing was done by the primary researcher.

Standard FMS (Table B4) testing procedures were used. Each participant was instructed to perform the 7 fundamental movements and 3 clearing tests. A movement was given a score between 0 and 3. A score of 1 indicated the inability to complete the movement, 2 represented compensation while completing the movement, and 3 signified a correct completion of the movement without compensation. The raw score was used to denote right and left side scoring. The final score denoted the overall score for the test. The lowest score for the raw score (each side) was carried over to give a final score for the test.

The LQYBT (Table B6) followed standard procedures. After the best of 3 trials in each direction were collected a composite score was calculated. The composite score was calculated by taking the average between right and left leg for the best reach distance in each direction and then summing the averages of the 3 reach directions. The score was then applied to leg length by calculating reach distance divided by right-limb length multiplied by 100 . Limb length was measured from the inferior anterior superior iliac spine to the inferior medial malleolus. Testing Protocol 
The Functional Movement Screen (FMS) (Table C) was designed to quantify the quality of a movement patterns. ${ }^{11}$ This is in contrast with the way many pre-participation performance/skills tests are evaluated, since most tests look at different variables in terms of quantity of variables. The goal of the FMS is to highlight movement limitations and/or asymmetries that might exist. The FMS is comprised of seven movements: squatting, stepping, lunging, reaching, striding/kicking, pressing/pushing, and crawling type movements. ${ }^{8}$ Reliability of the FMS has shown to be high $(\mathrm{r}=.98) .{ }^{12}$ Considering the FMS can be used to observe inefficiencies in movement patterns it is possible that the FMS could help to determine an athlete's risk for injury.

The first movement in the FMS (Table C3) was a deep squat and was designed to assess bilateral, symmetrical, functional mobility of the hips, knees, and ankles. ${ }^{9,11}$ A dowel was held overhead to assess bilateral symmetrical mobility of the shoulders and thoracic spine. The participant assumed a shoulder width apart stance and grasped the dowel so that the arms formed a 90 degree angle at the head. The individual then pressed the dowel overhead with the elbows in full extension. The participant was instructed to descend as far as possible into a squat while keeping heels on the ground and maintaining an upright torso. A one second pause at the bottom of the squat was completed before returning to the start position. The participant had a maximum of three trials to complete the movement to the best of her ability.

The second movement in the FMS (Table C3) was the hurdle step. ${ }^{8,11}$ This movement is designed to assess mobility and stability of the hips, knees, and ankles. The height of the hurdle was set to the height of the participant's tibial tuberosity. The participant (while holding a dowel behind the head and across the shoulders) was instructed to step over the hurdle with one leg, touch the ground on the other side of the hurdle (without accepting weight), and then return the leg back 
over the hurdle. This test was assessed bilaterally. The participant had a maximum of three trials to complete the movement to the best of her ability.

The third movement of the FMS (Table C3) was the in-line lunge. ${ }^{8,11}$ This movement was designed to assess quadriceps flexibility, hip mobility and stability, and bilateral ankle and knee stability.. The participant stood on a $2 \times 6$ board while holding a dowel behind the back. The dowel must maintain three points of contact (base of skull, thoracic spine, and sacrum) throughout the lunge. The opposite hand of the front foot was used to grasp the dowel at the head while the other hand was placed on the dowel in the lumbar spine. The height of the tibial tuberosity was used as the distance between the two feet. The back knee touched the board behind the front foot and the feet were kept in the sagittal plane during the lunge. This test was assessed bilaterally. The participant had a maximum of three trials to complete the movement to the best of her ability.

The fourth movement of the FMS (Table C3) was the shoulder mobility test. ${ }^{11}$ This movement was designed to assess shoulder range of motion. This test required normal scapular mobility and extension of the thoracic spine. ${ }^{13}$ The tester measured (in inches) the length of the participant's hand from the crease of the wrist to the end of the third finger. The participant was then instructed to close the fist, and maximally adduct, extend and internally rotate with one shoulder and maximally abduct, flex and externally rotate the other. The flexed shoulder is the side being scored. The tester then measured the distance between the two hands. The test was assessed bilaterally. The participant had a maximum of three trials to complete the movement to the best of her ability.

The shoulder clearing test (Table C3) was performed at the end of the shoulder mobility test. This movement was not scored but used to observe a pain response. This clearing test was necessary to detect impingement symptoms that can go undetected with the shoulder mobility test. 
The individual was instructed to place the hand on the opposite shoulder and attempt to point the elbow upward. If pain was produced, a score of zero was given for the test. The clearing test was performed bilaterally. ${ }^{9}$

The fifth movement in the FMS (Table C3) was the active straight leg raise. ${ }^{11}$ This movement was designed to assess active flexibility of the hamstrings and gastroc-soleus complex while maintaining a stable pelvis and core. ${ }^{13}$ The participant was instructed to lie on her back with the $2 \times 6$ board under her knees with the legs straight. The leg that was not being tested must remain in contact with the floor with the foot in a dorsiflexed position. The tester then identified the midpoint between the anterior superior iliac spine and midpoint of the patella. A dowel was placed perpendicular to the floor at the measured midpoint. While maintaining contact with the floor through the head and lower back, the participant was instructed to raise the test leg with a dorsiflexed ankle and extended knee as far as she could. If the malleolus did not pass the dowel, the dowel was moved in line with the malleolus of the test leg and scored per the criteria. This test was performed bilaterally. The participant had a maximum of three trials to complete the movement to the best of her ability.

The sixth movement in the FMS (Table C3) was the trunk stability push-up. ${ }^{11}$ This movement was designed to assess trunk stability while a closed-chain upper body motion was completed. The participant assumed a prone position with the hands spaced shoulder-width apart and the feet together. Females were instructed to place thumbs in line with the chin. The participant was then instructed to lift the body as a unit with the knees extended and ankles dorsiflexed to complete one push-up. If the participant was unable to complete the push-up, the hand position was moved level with the shoulders. The participant had maximum of three trials to complete the movement to the best of her ability. 
The spinal extension clearing test (Table C3) was performed after the trunk stability pushup. This movement was not scored but used to observe a pain response. The clearing test was necessary to detect back pain that can go undetected with movement screening. The participant was instructed to perform a press-up in the push-up position. If pain was produced, a score of zero was given for the test. ${ }^{13}$

The seventh movement in the FMS was the rotary stability test. ${ }^{11}$ (Table C3) This complex movement required proper neuromuscular coordination and energy transfer from one segment of the body to anther through the torso. ${ }^{13}$ The participant was instructed to assume a quadruped position with both hands and both feet on the ground at relatively 90 degree angles (shoulders relative to the upper torso; hips/knees relative to lower torso). The $2 \times 6$ board was placed between the knees and hands so that both the hands and knees were touching the board. The participant was then instructed to lift the arm and leg (flexes shoulder, extends hip) on the same side and attempted to touch the knee and elbow together. If the participant was unable to complete such a repetition, the pattern changed to a diagonal pattern (opposite arm and leg). This test was performed bilaterally. The participant had a maximum of three trials to complete the movement to the best of her ability.

The spinal flexion clearing exam (Table C3) was performed at the end of the rotary stability test. This movement was not scored but used to observe a pain response. The purpose of the clearing exam was necessary due to back pain going undetected by movement screening. Spinal flexion was cleared when assuming a quadruped position, and then rocking back to touch the buttocks to the heels and chest to the thighs. Hands remained in front of the body, reaching out as far as possible. ${ }^{13}$ If pain was produced, a score of zero was given for the test.

The testing procedures for the FMS have been previously defined by Cook. ${ }^{11}$ Individuals 
were limited to approximately three trials for each movement and an extensive warm up was not included. A script was read (Table C3) to ensure understanding of the movements that were being tested. Participants were not "cued" of their movements. The raw score was used to denote right and left side scoring. The final score was used to denote the overall score for the test. The lowest score for the raw score (each side) was then carried over to give a final score for the test.

The LQ-YBT (Table C6) is a version of the SEBT that measures dynamic balance during a single leg stance that requires strength, proprioception and flexibility. ${ }^{14,15}$ The participant was instructed to place the heel of the foot being tested on the line marked on the board. While balancing on the stance leg the participant was given three attempts to reach the furthermost point in the anterior direction. The posteriomedial and posteriolateral directions were tested following the same process. The participant was allowed three practice trials in each direction. After the practice trails, data was collected for the best of three trails in each direction. While maintaining balance the participant was instructed to reach in the anterior direction followed by posteriorlateral and posteriomedial directions. Rest time in between test directions and trials were based on the subject but did not exceed one minute. If errors were detected by the investigator the test direction was repeated.

Data Analysis

Using a coded system, the scores for the FMS were recorded (Table C5). The final score was calculated by taking the lowest score of movement with right and left values. The maximum score total is 21 . The values gathered were assessed within sport and with normative values of other sports.

On a separate coded sheet, the LQ-YBT values were recorded (Table C7). Right and left leg lengths were taken in centimeters from the anterior superior iliac spine to the inferior medial 
malleolus. The composite score was calculated by taking the average between right and left leg for the best reach distance in each direction and then summing the averages of the 3 reach directions. The score was applied to leg length by calculating reach distance divided by right-limb length multiplied by 100. On test completion of all subjects, values were entered into a spreadsheet on SPSS Version 22.0 for Windows. (SPSS Inc, Chicago, IL) Statistical Analysis

Descriptive analysis consisted of means and standard deviations of all subjects for the FMS and LQ-YBT (Table D2). To calculate predictors of injury other statistics including binary logistic regression, Cox Snell $\mathrm{R}^{2}$ and odds ratio were used with 95\% Confidence Intervals. A binary logistic regression was run producing a Cox and Snell pseudo R2 statistic. The higher the Cox and Snell pseudo R-squared statistic, the better the model fits the data. Three models provided the best fit. The $\mathrm{P}$ value was set at $\mathrm{P}=0.05$ for all analyses. Three models were used to indicate injury prediction. The first model compared Years of Competition and Total Accounted Injury. The second model compared the Final FMS Score, LQYBT Left and LQYBT Right scores. The third model compared the FMS Cut $(\leq 14)$ and Total Accounted Injury. The ability to predict outcomes or characteristics that may predispose an athlete to sustaining an injury can be useful both clinically and in applied settings.

\section{RESULTS}

Demographic Data

Twenty-two female athletes (age $19.25 \pm 0.91 \mathrm{yrs}$, height $161.97 \pm 7.03 \mathrm{~cm}$, weight $62.53 \pm$ $8.71 \mathrm{~kg}$ ) participating in a NCATA recognized acrobatics and tumbling team during the 2015-2016 season volunteered for this study. Ten (45.5\%) of the subjects who participated were a part of the freshman class, 7 (31.8\%) in the sophomore class, $4(18.2 \%)$ in the junior class and $1(4.5 \%)$ in graduate studies. None of the subjects had an injury status that prevented full participation in 
practices, meets or conditioning at the time of testing. Participation in a previous sport included gymnastics $(\mathrm{n}=5,22.7 \%)$ and cheerleading $(\mathrm{n}=17,77.3 \%)$ at a variety of levels. The gymnastic level and cheer experience were as follows: level 7-8 gymnast ( $\mathrm{n}=1,4.8 \%)$, level 9-10 gymnast $(n=4,19.0 \%)$, high school cheerleader $(n=5,23.8 \%)$ and all-star cheerleader $(n=11,52.4 \%)$. Position was broken into three categories, top $(n=6,27.3 \%)$, base $(n=15,68.2 \%)$ and middle $(n=1$, 4.5\%). Descriptive subject data including age, height, weight, and sport participation for all subjects is presented in Table D1. The mean FMS and LQYBT scores and standard deviation (SD) for all subjects $(\mathrm{n}=22)$ included in the study was $15.9 \pm 1.87$ (maximum score of 21), 98.36 \pm 11.63 (right) and $99.24 \pm 12.01$ (left). Table D2 presents the means and SD of FMS and LQYBT scores as broken down by position and totals.

Injury Epidemiology

Injury data was self-reported and included injuries that were sustained in the past six months and over the past three years. Injury information gathered in the last six months $(n=20)$ (Table D3) included ankle $(n=5,25 \%)$, heel $(n=1,5 \%)$, Achilles $(n=1,5 \%)$, calf/lower leg $(n=1$, $5 \%)$, knee $(\mathrm{n}=2,10 \%)$, quad $(\mathrm{n}=1,5 \%)$, spine $(\mathrm{n}=2,10 \%)$, sternum $(\mathrm{n}=1,5 \%)$, elbow $(\mathrm{n}=1,5 \%)$, wrist $(n=3,15 \%)$, thumb $(n=1,5 \%)$, and finger $(n=1,5 \%)$. The most common type of injury classification was sprains $(n=7,35 \%)$, contusions $(n=2,10 \%)$, strains $(n=3,15 \%)$, tendinopathy $(\mathrm{n}=2,10 \%)$, fractures $(\mathrm{n}=2,10 \%)$ and disc $(\mathrm{n}=2,10 \%)$. The most common mechanism of injury included tumbling $(\mathrm{n}=8,40 \%)$, overuse $(\mathrm{n}=3,15 \%)$, and stunting $(\mathrm{n}=6,30 \%)$. A total injury (Table D4) history going back three years revealed the following body parts, injury type and mechanism. The ankle $(n=22,40 \%)$ was the most injured body part followed by the knee $(n=6,11.3 \%)$, wrist $(\mathrm{n}=6,11.3 \%)$ and spine $(\mathrm{n}=4,7.5 \%)$. Sprains $(\mathrm{n}=28,52.8 \%)$ were the most frequent injury classification followed by fracture $(n=6,11.3 \%)$, strain and tendinopathy $(n=5,9.4 \%)$. The most 
common mechanisms of injury reported was tumbling $(n=22,40.7 \%)$, overuse $(n=12,22.2 \%)$ and stunting $(\mathrm{n}=7,13 \%)$.

Logistic Regression and Odds Ratios

A binary logistic regression was run producing a Cox and Snell pseudo R2 statistic. The higher the Cox and Snell pseudo R-squared statistic, the better the model fits the data. Three models provided the best fit. The 2 x 2 contingency table using the variables years of competition and total accounted injury produced a Cox and Snell $\mathrm{R}^{2}(0.276)$ and an odds ratio of 1.451 (CI95=0.980 to 2.149) for years of competition. This logistic regression model "moderately" fits the data and accounts for 27.6 percent of the variable predicting injury or not. The second $2 \times 2$ model used FMS final score, LQYBT Right and LQYBT Left variables. Cox and Snell R2 (0.259) and a non-significant $(\mathrm{P}=0.36)$ odds ratio of 1.983 (CI95=1.045 to 3.763) for FMS Final score. LQYBT odds ratios for the right and left leg were also not significant at $(\mathrm{P}=0.939)$ and $(\mathrm{P}=0.988)$, respectively. The third and most significant logistic model used the FMS cut-off score of 14, as described by Kiesel ${ }^{12}$ and total accounted injury. A 2 × 2 contingency table was produced with a Cox and Snell $\mathrm{R}^{2}$ (0.342) and significant $(\mathrm{P}=0.028)$ odds ratio of 28.335 (CI95=1.429 to 561.997) for FMS Cut $(\leq 14, \geq 15)$. Total accounted injury was not significant $(\mathrm{P}=0.084)$. This logistic model "moderately to good" fits the data and accounts for 34.2 percent, of the variation predicting injury or not. The odds ratio represents an athlete that scores $\leq 14$ with a history of multiple previous injuries has a 28-fold increase in likelihood of injury.

\section{DISCUSSION}

This study was performed to determine if compensatory movement patterns predispose female collegiate athletes to injury, and if the FMS or LQYBT could predict injury in the sample population. The hypothesis that compensatory movement patterns were related to injury was 
supported in the present study. A lower score on the FMS paired with total accounted injury (6mo or 3yr) was significantly associated with future injury, experiencing a 28-fold increase in injury risk when utilizing the cut-off score of 14 or less that was determined by Kiesel. ${ }^{12}$ However, using a cut-off score of $89 \%$ on the LQYBT was not able to predict injury nor when paired with the total FMS score.

Epidemiology and Injury Rates

Injury data was self-reported and included injuries that were sustained in the past six months and over the past three years. Documented injuries involved time loss or evaluation and treatment by an athletic trainer or physician. The most common injury documented was an ankle sprain that happened while tumbling. Reported injuries were conclusive to previous injury surveillance by Shields ${ }^{3-5}$ that stated ankle injuries were the most commonly reported injury in cheerleaders. Stunting and tumbling were reported as the mechanism of injury in the majority of cases. Tumbling mechanisms included landing off the mat, not landing a full twist, and misjudging height of the body during the skill. Stunting included tops who were dropped or bases that were landed on. Tumbling was the most reported mechanism, although previous research found stunting to be the leading cause of injury to the lower extremity of cheerleaders. ${ }^{3-5}$ This can be explained by the nature of the sport. A\&T involves more tumbling than stunt maneuvers and skills while the sport of cheerleading involves more stunting maneuvers than tumbling skills or series. The majority of documented overuse injuries were secondary to tumbling and stunting without adequate rest, change in position or skill of the top being supported.

Functional Movement Screen

As this is the first study to include acrobatics and tumbling, there were some similarities from previous literature in regard to FMS being able to predict injury. Kiesel ${ }^{12}$ tested professional 
male football players who, in addition to an elite athlete status, experienced different sport and training demands compared to the acrobatics and tumbling athlete counterparts. In addition, Kiesel ${ }^{12}$ limited data collection to "serious" injury, defined as membership on the injured reserve, and time loss of a minimum of three weeks from normal training and competition. Kiesel's ${ }^{12}$ retrospective study concluded that professional football players had a greater chance of suffering serious injury if the players score was below 14 with an odds ratio of 11.67 . The current study chose to adopt a more broad definition of injury. The first, the number of acrobatics athletes would not parallel those of a professional football team. Second, the contact and nature of football leading to a large number of severe and traumatic injuries is not present with the sport of acrobatics and tumbling. Lastly, the study wanted to include overuse and repetitive trauma injuries that may not have been accurately represented, yet can still be contributed to compensatory movement patterns and an increased risk of a more severe musculoskeletal injury. The basis for use of the FMS by $\operatorname{Cook}^{8-9,11,13}$ is a hypothesis that repetitive trauma caused by accepting inefficient movement strategies may predispose individuals to musculoskeletal injury. The effects of repetitive trauma include overuse pathologies that the athlete is initially able to work through despite symptoms.

When comparing those numbers to the tested population the majority of subjects surpassed the cut value, the participants in this study were able to make up for unilateral strength deficits by scoring higher on flexibility and bilateral tests. When compared to other studies, similarities were found in the female population. Chorba ${ }^{15}$ applied the FMS to collegiate females seeking to determine if the tool could be used to predict injuries in the specific population. A linear regression analysis established a predictive relationship between the FMS score and risk for injury in subjects who had not undergone an anterior cruciate ligament reconstruction. A score of 14 or less on the FMS resulted in a 4 -fold ${ }^{15}$ increase of lower extremity risk of injury over the course of a 
competitive season in collegiate female athletes. These findings along with the Chimera study ${ }^{16}$ may indicate that female athletes have an increased injury risk when decreased core stability is present. Chimera ${ }^{16}$ found that female and male athletes performed similarly on the overall FMS score, however the final composite score was not achieved in the same manner. Females showed lower scores in tasks that involved greater core coordination and energy transfer while having higher scores in tasks that involved greater flexibility and mobility ${ }^{16}$ as seen with the subjects in this population. Although, this study focused on female acrobatics athletes, the previous assessment can be concluded. There were similar findings found by Schneiders ${ }^{17}$ who assessed recreational athletes. Results from Schneiders ${ }^{17}$ study showed no significant difference between male and female scores on the FMS. In that study, therefore, future research should include the evaluation of sex biases and the association between FMS composite scores and injury. Although, previous studies used the FMS as a predictor of injury, injury history has been suggested as the best predictor of injury risk. ${ }^{19-20}$ However, this was not the case in this study, as athletes who scored less than 14 on the FMS have experienced a higher proportion of injuries, ${ }^{12,15,18}$ and was the best predictor with a 28 -fold increase in likelihood of injury.

When evaluating individual scores, the subjects in this study were primarily lower-extremity dominant in nature. A trend was noted regarding the performance of the Active Straight Leg Raise, Deep Squat and Hurdle Step in female subjects. The majority of subjects $(64 \%, n=14)$ obtained the highest score of 3 on the Active Straight Leg Raise test, with many greatly exceeding the required measurements for hamstring/low back flexibility. The majority $54.5 \%(n=12)$ scored the highest of a 3 on the Deep Squat. Conversely, only $13.6 \%(n=3)$ scored a 3 on the Hurdle Step. When comparing scores of the Deep Squat and Hurdle Step, it is assumed that single leg activities are more difficult and show a better representation of inefficient movement. If following the Kiesel ${ }^{12}$ 
study to produce a cut-off score of 14 for the FMS, an individual could score at least a 2 on each of the seven scored tests to remain above the cut point value.

Lower Quarter Y-Balance Test

Athlete position and dynamic balance is based on the varying stunting and spotting techniques required for stunts, tosses and pyramids in the sport of A\&T. Proprioceptive abilities have an impact on athletic participation. The mean composite scores were broken down by position. Tops $(105.36 \pm 18.90,103.54 \pm 17.56)$ produced better results than their base counterparts (97.24 $\pm 8.08,96.47 \pm 8.77$ ). This can be assumed based on the positional requirements, however, there were more athletes that identified as a base other than a top. Thus, explaining why the mean subject score more resembles that of the bases. Tops spend more time in single leg stunts while bases use both extremities as a base of support to build, toss and spot. Athletes that have a higher degree of proprioceptive ability are less likely of incurring an injury than athletes with less proprioceptive ability.

As was completed for the FMS, a cut off score for the LQYBT was also used following the protocol established by Butler ${ }^{21}$ at $89 \%$. Evidence showing sensitivity (100\%) and specificity (71.1\%) were maximized using $89.6 \%$ of the composite score to predict injury in football players. Scores less than $89.6 \%$ were associated with an injury risk that was 3.5 times greater. The majority of subjects $22.7 \%(n=5)$ scored $89 \%$ or below on the composite score for the right and left. Although, Chimera ${ }^{16}$ did not use a cutoff score of $89 \%$, all female athletes from varying sports teams were above the cutoff score. Chimera ${ }^{16}$ found that Cheer and Dance subjects had composite scores of $97 \pm 8$ which is comparative to the results found with the participants in this study with right composite scores of $98 \pm 11.6$ and left composite scores of $99 \pm 12$. These numbers suggest that flexibility and mobility of the lower extremity required for these sports can produce higher composite scores on the LQYBT. 
Variables from the Questionnaire in Predicting Injury

Other variables that could increase risk of injury were documented on the questionnaire. Although not significant statistically, the thought was that increased tumbling skills and tumbling series can predispose athletes to injury based on highest tumbling skill and series. Thus, indicating that athletes with a tumbling pass that has a total of 6 elements are more likely to get injured compared to their counterparts who only have a 3 element pass. The higher the skill, the more points awarded. With that in mind, there are more athletes attempting skills never attempted before in hopes of increasing team point values.

Clinical Implications/Limitations

The FMS and LQYBT can be used by clinicians to determine injury risk in athletes. In this population however, the demands and nature of sport do not correlate to previously tested counterparts in the collegiate setting. The FMS can still be used to identify athletes at risk in this population when including the previous injury of subjects. While this population differs in many aspects of traditional athletics, it can still be utilized. Deficits in movement, compensations and dynamic stability can be detrimental when supporting the weight of another person, thus the vital role of identification to protect all positions. Through identifying problem areas, an individualized corrective program can be administered to address those specific needs. As a high level of competition and performance is reached, the risk for injury increases. If injury risk can be identified based on scores, prevention strategies can be better implemented to increase performance efficiency and decrease compensation.

Although this study was only partially successful in establishing a predictive utility for the FMS in acrobatics and tumbling athletes, observation of a limited sample and lack of injury surveillance may not have provided the appropriate framework from which to draw conclusions. Future studies incorporating a larger, more diverse sample of female collegiate acrobatics and 
tumbling athletes along with injury surveillance and pre-post testing are warranted in order to determine if the FMS and LQYBT can be used to predict injury and generalize to the population of female collegiate acrobatics and tumbling athletes. Future studies may also find that certain components of the FMS may be used independently or concentrate on right and left sided scoring to predict injury. However, the concept of energy transfer throughout the kinetic chain underscores the appropriateness of administering the entire test battery within the FMS ${ }^{\mathrm{TM}}$ as the complex interaction of core stability with distal extremity control is required in most sporting activities.

\section{CONCLUSION}

Compensatory fundamental movement patterns can increase the risk of injury in female collegiate athletes, and can be identified by using the Functional Movement Screen. A score 14 or less on the FMS paired with total accounted injury resulted in an approximate 28-fold (1.429 to 561.997) increase in risk of injury over the course of a competitive season in female collegiate athletes participating in acrobatics and tumbling. The LQYBT composite score for right and left side did not predict injury risk when paired with the final FMS score. 


\section{REFERENCES}

1. National Collegiate Acrobatics and Tumbling Association. 2011. Available at http://thencata.org/landing/index. Accessed December 3, 2015.

2. Hutchinson MR. Cheerleading injuries, patterns, prevention, case reports. Phys Sports Med. 1997;25(9):83-96.

3. Shields BJ, Smith GA. Cheerleading-related injuries in the United States: a prospective surveillance study. J Athl Train. 2009; 44(6):567-577.4.

4. Shields BJ, Smith GA. Epidemiology of cheerleading stunt-related injuries in the United

States. J Athl Train. 2009; 44(6):578-585.

5. Shields BJ, Fernandez SA. Epidemiology of cheerleading fall-related injuries in the United States. J Athl Train. 2009; 44(6):586-594.

6. Jacobson BH, Hubbard M, Redus B. An assessment of high school cheerleading: injury distribution, frequency, and associated factors. J Orthop Sports Phys Ther. 2004;34(5):261-265.

7. Boden BP, Tacchette R, Mueller FO. Catastrophic cheerleading injuries. Am J Sports Med. 2003;31(6):881-888.

8. Cook EG, Burton L, Hoogenboom BJ. Pre-participation screening: The use of fundamental movements as an assessment of function-Part 1. N AM J Sports Phys

Ther. 2006;1(2):62-72.

9. Cook EG, Burton L, Hoogenboom BJ. Functional movement screeing: The use of fundamental movements as an assessment of function-Part 1. Int J Sports Phys Ther. 2014;9(3):396-409.

10. Peate WF, Bates G, Lunda K, Fransis S, Bellamy K. Core strength: a new model for injury prediction and prevention. J Occup Med Toxicol. 2007;2:3.

11. Cook G. Movement: Functional Movement Systems, Screening - AssessmentCorrective Strategies. Lotus Publishing; 2011.

12. Kiesel K, Plisky PJ, Voight ML. Can serious injury in professional football be predicted by a preseason functional movement screen. N Am J Sports Phys Ther. 2007;2:147-158.

13. Cook EG, Burton L, Hoogenboom BJ. Functional movement screeing: The use of fundamental movements as an assessment of function-Part 2. Int J Sports Phys Ther. 2014;9(4):549-562. 
14. Shaffer SW, Teyhen DS, Lorenson CL, Warren RL, Koreerat CM, Straseske CA, Childs JD. Y-Balance Test: a reliability study involving multiple raters. Mil Med. 2013;178(11):1264-70.

15. Chorba RS, Chorba DJ, Bouillon LE, Overmyer CA, Landis JA. Use of a functional movement screening tool to determine injury risk in female collegiate athletes. $N$ AM J Sports Ther. 2010;5(2):47-54.

16. Chimera N.J., Smith C.A., \& Warren M. (2015). "Injury History, Sex, and Performance on the Functional Movement Screen and Y Balance Test." J Athl Train 50(5): 475-485.

17. Schneiders AG, Davidsson A, Horman E, Sullivan SJ. Functional Movement Screen normative values in a young, active population. Int J Sports Phys Ther. 2011;6(2):7582.

18. O’Connor FG, Deuster PA, Davis J, Pappas CG, Knapik JJ. Functional movement screening: predicting injuries in officer candidates. Med Sci Sports Exerc. 2011;43(12):2224-2230.

19. McKay GD, Goldie PA, Payne WR, Oakes BW. Ankle injuries in basketball: injury rate and risk factors. Br J Sports Med. 2001;35(2): 103-108.

20. McHugh MP, Tyler TF, Tetro DT, Mullaney MJ, Nicholas SJ. Risk factors for noncontact ankle sprains in high school athletes: the role of hip strength and balance ability. Am J Sports Med. 2006;34(3): 464-470

21. Butler RJ, Lehr ME, Fink ML, Kiesel KB, Plisky PJ. Dynamic balance performance and noncontact lower extremity injury in college football players: an initial study. Sports Health. 2013;5(5):417-422 
APPENDICES 


\section{APPENDIX A \\ THE PROBLEM}

Research Question

Acrobatics and tumbling (A\&T) is a new sport that has started to attract attention in the collegiate setting. A\&T can be described loosely as an evolution of gymnastics skills such as the toss, acrobatic lifts, pyramids and tumbling. The base of recruitment pulls from disciplines including artistic gymnastics, acrobatic gymnastics, trampoline and tumbling, youth team acrobatics and tumbling and high level competitive cheer teams. The majority of team members come from gymnastics and cheerleading backgrounds. There are a total of six events, each event has three to six heats. Point values for each event and heat are based on the level of difficulty; thus, a higher point value will be assessed for increasing skill difficulty. Based on meet format there are at least twelve stunt related skills through four events not including the team performance.

As A\&T continues to grow as a sport, the importance of injury tracking and reporting needs to be addressed along with the tools to help identify those at an increased risk. There is currently no specific research in the prevention of injuries associated with the sport of acrobatics and tumbling. Furthermore, no specific screening tool exists for A\&T. The functional movement screen and lower quarter Y balance test are two possible screening tools to use, but both have not been applied to this population specifically.

Athletes today are working harder to become stronger and faster which can often lead to compensatory movement strategies in order to achieve high performance. Inefficient movement strategies have the opportunity to reinforce poor biomechanical movements during activity, 
increasing injury risk. ${ }^{12}$ The inefficiency of fundamental movement can lead to a decrease in performance, added dysfunction and increase in injury. ${ }^{9,13}$

The assessment of performance function has gradually progressed to the front line of preparticipation screening. The bridge came when Cook $^{11}$ developed the Functional Movement Screen (FMS). The purpose of a movement screen is to identify at-risk athletes, improve movement patterns, monitor progress of movement and provide a baseline to clinicians so a specific program can be implemented to address weakness. ${ }^{8,21}$

Sport activity is rarely ever static in nature, the dynamic component of proprioception is vital. Kinesthesia can be described as the sense of joint motion and acceleration comprising the dynamic component of proprioception. Dynamic proprioception involves mechanoreceptors in each joint giving the athlete the neuromuscular ability to sense joint position and movement. A combination of mechanical instability, deficits and/or compensatory proprioceptive skills can contribute to the functional instability of a joint. This instability increases the risk for acute or chronic injury.

The problem is injuries occur to A\&T participants. No screening tool exists to predict injury or to look at deficits and dysfunctional movement. The FMS and LQYBT may be used based on what movements exist with the sport of A\&T and the purpose of the screening tools. The LQYBT is a dynamic tool used to asses balance and proprioception. Although not used to predict injury the test can provide information on select individuals who are at an increased risk for injury.

The functional assessment of performance movement patterns have been integrated into pre-participation physicals to identify areas of functional deficit. The physical demands of the sport of acrobatics and tumbling have not been assessed in the literature. While the importance 
of fundamental movement and dynamic proprioceptive stability can be expressed, there is little information available regarding application of the FMS and LQYBT to acrobatics and tumbling as an accurate tool for predicting injury risk.

Thus, the following research questions are asked:

Research Questions

1. Does a higher skill level affect injury risk?

2. Is there a difference between gymnast and cheerleader scores?

3. Does the FMS accurately detect athletes at risk for injury?

Experimental Hypothesis

1. Upperclassmen will have higher scores on the FMS and LQYBT?

2. Gymnasts will have higher scores on the FMS and LQYBT.

3. Scores below 14 will predict subjects with injury risk.

Assumptions

1. All subjects will meet the inclusion criteria for the research study.

2. FMS and LQYBT are valid and reliable.

3. The documentation of each subjects' testing score will be accurate.

4. All subjects will listen, understand and perform the tests to the best of their ability.

Delimitations

1. Subject population is specific only to collegiate acrobatics and tumbling athletes.

2. This study is not generalized to other age groups other than a population aged $18-23$ and to one acrobatics and tumbling team. 


\section{Operational Definitions}

1. Acrobatics and Tumbling - Evolution of the different forms of gymnastics that includes tumbling, toss, acrobatic lifts and pyramids. ${ }^{1}$

2. Base - Athlete who is in direct, weight-bearing contact with the mat surface and provides the primary support for another athlete. ${ }^{6}$

3. Cheerleader - Individual involved in high school or competition cheer with involved stunting, pyramids and tumbling included. ${ }^{3-7}$

4. Direct Contact Injury - Acute injury that resulted in contact with another athlete. ${ }^{3-5}$

5. Flier (top)-A person who leaves the ground for the purpose of a stunt, pyramid or toss. ${ }^{3-5}$

6. Functional Movement Screen (FMS) - A set of seven physical tests that assess mobility, strength and coordination to determine an individual's compensation patterns and/or deficiencies in movement patterns. ${ }^{11,13,22}$

7. Gymnast - Individual who is trained in gymnastics and has competed in levels of competition. (Level 10 being the highest)

8. High Skill - The routine completion of advanced tumbling. For the purpose of this study anything containing a full twist or higher will be accepted.

9. Injury - Injury meeting three criteria (a) injury occurred in practice/competition/conditioning program; (b) injury required medical attention by athletic trainer or team physician; (c) injury prevented or altered participation in organized practice/competition/conditioning program for one or more days post injury. ${ }^{3-5}$

10. Injury Risk - The probability of an injury to occur

11. Non-Contact Injury-Injury that occurred in the absence of contact with another athlete..$^{3-7}$

12. Normal Skill - Routine completion of ordinary skill. This will include all skills under a full twist.

13. Overuse Injury - Chronic injury with insidious onset with no definitive time of occurrence.

14. Spotter - Athlete in direct contact with the mat surface who may help the building of, or dismount from a stunt. ${ }^{3-7}$

15. Underclassman - A freshman or team member who is in their first year of competitive collegiate acrobatics and tumbling.

16. Upperclassman - A team member who is a sophomore/junior/senior with at least one year in competitive collegiate acrobatics and tumbling. 
17. Y Balance Test (YBT) - A dynamic measure of balance and proprioception serving as a predictor of lower extremity injury. ${ }^{21}$

\section{Limitations}

1. Participant can drop out of the study at any time.

2. Participants are subject to selection bias.

3. Threats to internal and external validity.

4. Non-certified FMS instructor.

5. Non-certified YBT instructor.

\section{Significance of Study}

No central data system is in place to track the number of injuries that occur to acrobatics and tumbling athletes during the course of a traditional school year. The importance of identifying the correct screening tool will help to provide athletic trainers the ability to identify and treat at risk female athletes. With available data information collected, preventative measures and screening tools may be developed or utilized to lower the injury rate of acrobatic and tumbling athletes. The assessment of compensatory movement patterns and balance are at the forefront of pre-participation screenings and the enhancement of performance strategy. The movements that are involved in the sport of acrobatics and tumbling resemble traditional athletic movements but also have aspects that only a certain type of strength and mobility can provide to complete the skill. The screening results are used to identify compensatory movement and deficits. Deficits in movement, compensations and dynamic stability can be detrimental when supporting the weight of another person, thus the vital role of identification to protect all positions. Through identifying problem areas, an individualized corrective program can be administered to address those specific needs. As a high level of competition and performance is 
reached, the risk for injury increases. The body's reaction to stress and growth can be detrimental if biomechanical imbalances are present.

The importance of this research is to take a functional screening tool and proprioceptive tool and apply it to a new population; acrobatics and tumbling. Although closely related to gymnastics and cheerleading, new skills and positions have to be taught and learned by the athletes. The high impact and high repetition involved can negatively impact these athletes. The utilization of a screening tool to functionally assess the performance of movement and dynamic stability can be used for injury prediction in this population and help to generalize results across the sport.

At the completion of this study, dissemination of information will occur. This information is vital in assessing the proper function of athletes in relation to sport. Due to the limited research within this population, this could help guide rehabilitation programs, pre- participation activity and athlete performance. The research will be presented at workshops and seminars at local universities. 


\section{APPENDIX B \\ LITERATURE REVIEW}

Introduction

The sport of Acrobatics and Tumbling (A\&T) is relatively new at the collegiate level, with competition beginning in the spring of 2011. ${ }^{1}$ A\&T can be described as the evolution ${ }^{1}$ of the different forms of gymnastics which involves tumbling, tosses, acrobatic lifts and pyramids. ${ }^{1}$ There are currently thirteen collegiate programs recognized by the National Collegiate Acrobatics and Tumbling Association (NCATA). ${ }^{1}$ Participants include institutions from all levels (division I, II and III) ${ }^{1}$ of the National Collegiate Athletic Association (NCAA). A\&T is considered an emerging sport, however, the sport does not receive recognition by the NCAA. Although the recruiting base is broad the majority of athletes come from gymnastic and cheerleading backgrounds.

Teams compete in a total of six events including: compulsory, acrobatic, pyramid, toss, tumbling and team routine. ${ }^{1}$ In the compulsory event each team will compete the same predetermined set of skills which will include toss, acrobatic, pyramid and tumbling heats. ${ }^{1}$ The acrobatic event contains three different heats of five, six and seven element acrobatic skills. This event is characterized by acrobatic movements that demonstrate base strength and flexibility of the athlete on the top. ${ }^{1}$ Event three is the pyramid. Each team will compete a unique pyramid sequence of varying difficulty. ${ }^{1}$ The pyramid event consists of three heats, each valued at ten points. A halftime of fifteen minutes is taken at the midway point of the competition as with all other collegiate sports. The toss event follows intermission. This high flying event consists of three bases that toss a flier (top) in the air while completing a sequence of flips or twists. ${ }^{1}$ There are three toss heats that have the potential to score ten points each. Event five consists of six tumbling heats all valued at ten points based on level of difficulty. ${ }^{1}$ This event contains high 
flying power that features multiple flips and twists. ${ }^{1}$ There are three synchronized heats that involve a duo, trio and quad. The other heats include a five element pass, six element pass and an open pass. The team event is a two and a half minute choreographed routine that encompasses skill sets performed in previous five events. ${ }^{1}$ There are three judges present for each competition. There are particular deductions for each event and heat that can affect scoring. A team can score up to a total of three hundred points, with the higher scoring team being declared the winner. Collegiate A\&T like cheerleading teams only use mats on a wooden or concrete floor for competition.

The sport of gymnastics and cheerleading has modernized a tremendous amount in the last thirty to fifty years. Cheerleading evolved from toe-touches and crowd involvement to the incorporation of stunting and tumbling. ${ }^{4}$ Cheerleading has become similar to gymnastics in terms of the tumbling that is now being incorporated into routines. Compared to other sports, cheerleading injuries have not received the same attention with regard to tracking and reportability. ${ }^{6}$ The increase in difficulty of maneuvers being performed has been accompanied by an increase in injuries. ${ }^{2}$ Since the sport of A\&T closely resembles the sports of cheerleading, this review of literature will discuss the importance of epidemiology, etiology, the FMS, reliability, stability and mobility, and the LQYBT.

Epidemiology

A prospective surveillance study by Shields ${ }^{3}$ concluded that the majority of injuries (83$85 \%$ ) occurred in practice due to the repetitive attempts and installation of new skills. The lower extremity was injured most often. Of the injuries sustained the ankle (12-16\%), ${ }^{3-5}$ knee (9$10 \%),{ }^{3-5}$ neck $(9-10 \%),{ }^{3-5}$ low back $(7 \%)^{3-5}$ and head $(7 \%)^{3-5}$ are the most common body parts injured. The type of injury was classified as a sprain or strain (53-54\%), ${ }^{3-5}$ contusion (13\%), ${ }^{3}$ fracture (10\%), ${ }^{3-5}$ concussion or other head injury (4-11\%). ${ }^{3-5}$ The most common mechanisms for 
injury included basing or spotting (24-34\%), ${ }^{3-4}$ failure to complete a skill $(15 \%),{ }^{3}$ tumbling $(15 \%),{ }^{3}$ and falls from height (14-20\%).,5 The top 5 injuries reported by Shields that cheerleaders sustained were ankle sprain or strain $(11-15 \%),{ }^{3-5}$ neck strain or sprain $(7-13 \%),{ }^{3-5}$ lower back strain or sprain $(5-10 \%),{ }^{3-5}$ knee strain or sprain $(5 \%)^{3-5}$ and wrist strain or sprain $(4 \%){ }^{3}$ Ankle strains and sprains were the most frequent injury assessed (15-24\%)., ${ }^{3,5-6}$

Shields ${ }^{4}$ was the first to research the specific epidemiology of stunt related injuries in cheerleading. The gymnastic element of cheerleading, specifically stunting and pyramids is thought to be associated with the greatest risk for cheerleading injury. ${ }^{4}$ The assumption is that a base is more inclined to injury due to the amount of catching, lifting, tossing and spotting that is assigned to the position. Compared to other types of stunt maneuvers, falls were more likely to occur when the cheerleader was attempting a single leg stunt. ${ }^{4}$ Falls most often resulted in neck injuries (17\%). ${ }^{4}$ Stunt-related injury accounted for $60 \%$ (338/567) of sustained injuries $(0.57$ injuries per 1000AEs). ${ }^{4}$ The most frequently attempted skill at the time of injury was a cradle (31\%) The stunt being performed during most injuries $(82 \%)^{4}$ was a mastered skill. College cheerleaders had the highest rate of injury per 1000AEs at 1.59 compared to high school 0.59 and All Star $0.36^{4}$

Another intensive study by Shields ${ }^{5}$ assessed fall-related injuries. Of the falls reported, spotters were actively engaged in the maneuver $62 \%$ of the injury event. This high percentage can be linked to the stunt-related research and the increased risk of injury for bases and spotters. Most of the falls occurred while the athlete was attempting a stunt or pyramid ${ }^{5}(89 \%)$, and single-leg stunts accounted for $28 \%$ of injuries. ${ }^{5}$ Forty-three percent of the injuries reported with 
falls involved more than one athlete. The most common mechanisms of injury associated with falls include: landing on another athlete (47\%), another athlete landed on the injured athlete (18\%), an athlete served as a base for the injured athlete (12\%) and the injured athlete was being caught by another athlete(s) $(6 \%)^{5} \quad$ Strains and sprains accounted for $54 \%$ of the reported injures. ${ }^{5}$ The ankle (18\%) and neck (13\%) were the most common sprains and strains accounted for. Pyramids and partner stunting accounted for $89 \%$ of fall-related injuries in Shields ${ }^{5}$ research, while Shultz ${ }^{23}$ found $56 \%$ of fall-related injuries were primary injuries of stunt related maneuvers.

The concussions reported during stunt related activities accounted for an injury rate of 0.04 per 1000 AEs. ${ }^{4}$ Thirty-one of fifty-nine cases described by Mueller and Cantu ${ }^{24}$ included the word fall as a descriptor of injury. Head injuries were results of 24 of the falls described. Boden ${ }^{7}$ found that of the most common stunts performed at the time of 29 cheerleading catastrophic injuries, 9 were pyramids and 8 involved the basket toss. Among the 29 catastrophic injuries, 17 were severe head injuries, resulting in 13 skull fractures, 2 deaths, and 8 were cervical fractures. Boden ${ }^{7}$ noted that high school cheerleaders have a greater risk of sustaining a concussion compared to their collegiate counterparts. However, the rate of catastrophic injury was significantly higher for collegiate cheerleaders in relation to high school cheerleaders. Pyramid and stunt height for collegiate cheerleading and A\&T range from 1.5-2.5 levels high. MaCarthur ${ }^{25}$ established that the risk of severe injury increased 2-fold for falls more than 4.9 feet.

The highest overall injury rate in collegiate cheerleaders (2.4-10.0 injuries per 1000 AEs) agrees with those results from other collegiate sports. However, in comparison, cheerleading was lower than other reported sports per 1000 AEs: women's gymnastics (6.1-15.2), women's basketball (4.0-7.7) and women's soccer (5.2-16.4). ${ }^{3}$

\section{Etiology}


Shultz et al ${ }^{23}$ reported the most common mechanism of injury in North Carolina high school cheerleaders was a fall from height $(25 \%)$ or contact with another athlete $(25 \%)$. This study focused on risk factors and incidence of concussions. The results showed that two-thirds of the cheerleading concussions resulted from females falling from pyramids. Cheerleading was the only sport which showed a higher injury ratio for practice than in games. The authors discussed being judged at competitions as a reason for higher risk during practices. Higher risk directly correlates with increased start values of high level stunt maneuvers and combinations. ${ }^{23}$ Falls onto an impact-absorbing surface are less likely to result in a serious injury. ${ }^{22,25}$ The potential of life-threatening head-impact injury can be decreased by increasing the shock-absorption capacity of the surface. $^{26}$ Jacobson, however, reports no relationship between the amounts of time spent at practice and the rate of injury. ${ }^{6}$

Functional Movement Screen

The Functional Movement Screen was developed by Cook ${ }^{8,11,13}$ in an effort to bridge the gap between pre-participation medical screening and performance testing. There are a variety of factors that predispose athletes to injury that include gender, agonist/antagonist ratio for strength and endurance, fitness level, structural abnormalities and history of prior injury. New research has introduced neuromuscular control, core instability, and contralateral muscular imbalance as other important intrinsic risk factors for injury.

This screening tool was designed to challenge the interactions of kinetic chain mobility and stability necessary for performance of fundamental, yet functional movement patterns. The adoption of inefficient movement strategies can reinforce poor movement patterns that regardless of achieving high performance can eventually lead to injury. The functional movement screen 
(FMS) has been used by professionals in the field of exercise and sport performance to analyze the movement capabilities of an athlete. The FMS consists of a series of seven fundamental movement patterns and three clearing tests ${ }^{8-9,11,13,22}$ that are performed by the athlete and scored by a certified professional. The FMS was designed to observe possible inefficiencies and deficits in an athlete's fundamental movement patterns. Athletes often use compensatory movements to achieve a higher level of performance ${ }^{12}$ There is a biomechanical difference between efficient movement and inefficient movement that may help to improve performance. There is limited research of the FMS at this time with the majority of research having been conducted on the observation of injury risk. An athlete's risk for injury may depend on any number of factors. Movement inefficiency or deficit may be potential risk factors for any athlete. Reliability

Reliability of the FMS has shown to be high $(\mathrm{r}=.98) .{ }^{12}$ Considering the FMS can be used to observe inefficiencies in movement patterns it is possible that the FMS could help to determine an athlete's risk for injury. According to Kiesel, ${ }^{8}$ the FMS may be able to identify an athlete that is at an increased risk of a non-contact injury. Kiesel found that NFL players having a total functional movement screen score of 14 or less prior to the start of season, had an increased risk for a serious injury throughout the season. ${ }^{12}$ Teyhen ${ }^{27}$ established the interrater reliability among novice raters as moderate to good reliability ( $\mathrm{ICC}=0.74$ and 0.76 ). Agreement between scores ranged from moderate to excellent $(\mathrm{K}=0.29-0.82) .{ }^{27}$ Another study using the FMS, took 433 firefighters through the FMS and determined that previous musculoskeletal injury was associated with a lower total FMS score. ${ }^{10}$ There is one study that examined the direct relationship between functional movement and athletic performance. ${ }^{28}$ Researchers in this study conducted core stability tests, a functional movement screen, and athletic performance tests on healthy 
recreational athletes. The study concluded that functional movement was not a strong predictor of athletic performance ${ }^{28}$ even though there was a significant correlation, the values were moderate to weak. Inefficient movement measured by the FMS, could potentially result in an increased risk for injury. It is important for the clinician to understand the cause of this inefficient and compensatory movement. In order to better understand movement deficits, it is important to discuss the role of stability and mobility for proper movement.

Chorba $^{15}$ applied the FMS to collegiate females seeking to determine if the tool could be used to predict injuries in the specific population. A linear regression analysis established a predictive relationship between the FMS score and risk for injury in subjects who had not undergone an anterior cruciate ligament reconstruction. A score of 14 or less on the FMS resulted in a 4-fold ${ }^{15}$ increase of lower extremity risk of injury over the course of a competitive season in collegiate female athletes.

Stability and Mobility

Each movement pattern assessed in the FMS requires a specific amount of stability and mobility to be performed correctly. Stability is considered to be strength, coordination, and control around a joint. ${ }^{29}$ Stability is important in creating efficient movement around a joint. Stability around a joint requires a specific amount of strength within the muscles. Stability and lack of stability have different effects on the body's strength and performance factors. Mobility is considered to be freedom of movement around a joint. ${ }^{29}$ Similar to stability, mobility is important in creating efficient movement. It has also been observed that at least four weeks of a 
program designed to increase mobility helped to increase range of motion and peak torque of the musculature. $^{29}$

Stability and mobility are directly related. The more stable a joint is the less mobile it will be, while the more mobility a joint has the less stable it will be. Consider the shoulder and hip, both are considered a ball-and-socket joint. The hip is more stable but less mobile than the shoulder whereas the shoulder is less stable and more mobile. Mobility and stability, around a joint during movement, are required to complete the movements in the functional movement screen. Each of the seven movements requires specific biomechanical factors of the human body segments. It is extremely helpful to understand these movement demands of the FMS on the body and how they may or may not have an effect on athletic performance.

The deep squat movement is a closed kinetic chain movement requiring proper mobility and stability to perform correctly. The deep squat is a bilateral movement and requires the athlete to perform symmetrical movement on both sides of the body in order to be performed. The athlete must show dorsiflexion in the ankles, knee flexion, and hip flexion as they sit into the squat. Keeping the arms from reaching over the toes requires thoracic spine extension and shoulder external rotation to occur. ${ }^{8-9}$ The squat movement is required for all sports and is the fundamental position of an athletic stance. Limited mobility in the upper torso can be a secondary cause of poor glenohumeral or thoracic mobility. ${ }^{8-9}$

The hurdle step movement is a unilateral movement which requires the athlete to stabilize the body on a single leg while moving the opposite leg. The hurdle step is a similar movement to walking or running and is designed to challenge proper stride biomechanics. ${ }^{9}$ One side of the body experiences hip flexion, knee flexion, and open-chain dorsiflexion of the ankle while at the same time the other leg requires stability. The hip, knee, and ankle on the opposite side of the movement 
are all stabilizing. Considering one leg is doing the opposite of the other leg the subject must be able to control asymmetrical movement within the hip joint. ${ }^{8}$ Asymmetrical leg movements are common for athletes to perform in sports and require stability of the down leg. Adequate balance must be displayed because the test imposes the need for dynamic stability. Athletes that have better strength, flexibility, and single leg stability have been observed to perform better in their respective sport. ${ }^{30}$ Training programs aimed at improving these attributes have been found to improve athletic performance, biomechanics, and single-leg stability of athletes. ${ }^{30-31}$

The in-line lunge movement is the second unilateral movement which requires the subject to stay balanced through full motion. The in-line lunge requires hip mobility in flexion and extension, knee flexion and extension, and closed-chain dorsiflexion of the ankles. This movement will also challenge hip stability in abduction in order to stay balanced in a lunge position. The lunge movement focuses on the stresses simulated during rotational, decelerating and lateral type movements. $^{9}$

The shoulder mobility movement requires mobility of the shoulder joint, shoulder girdle, and thoracic spine. Shoulder internal rotation and adduction take place on one side while the opposite side is in shoulder external rotation and abduction. The movement requirements for the shoulder mobility movement are asymmetrical although it is a bilateral movement ${ }^{8-9}$ Athletes that perform continuous repetitions of overhead movement on one side may develop asymmetrical biomechanical differences. Increased external rotation is gained at the expense of internal rotation in overhead athletes. ${ }^{9}$ The excessive muscular development of the chest can shorten the pectoralis minor and latissimus dorsi causing forward head and postural abnormalities. Scapulothoracic dysfunction is a result of decreased glenohumeral mobility and stability. These differences may be associated with an increased risk for shoulder injuries. $8-9,11,13,22$ 
The active straight leg raise movement requires the subject to move a single leg into hip flexion while lying supine. This requires hamstring flexibility and gastrocnemius/soleus flexbility of the leg. The opposite leg will stay on the ground during the movement and must be in a neutral position. An increase in flexibility in the hamstring muscle group has been shown to increase performance. Poor performance can be the lack of functional hamstring flexibility. Inadequate mobility of the opposing hip secondary to iliopsoas inflexibility can be associated with an anterior tilted pelvis. $^{22}$

The trunk stability push up is designed to test the ability of the athlete to stabilize the core and spine in a closed chain movement. ${ }^{22}$ The movement requires the muscles of the core to stabilize the trunk in all three planes of motion while a push up is performed. This movement is symmetrical, therefore, it requires proper stability in the shoulders. ${ }^{13} \mathrm{King}^{32}$ discusses that stabilizing the trunk and core prior to the movement of extremities creates a more efficient movement pattern and decreases the risk for injury. If there is inadequate stability during activity and energy transfer, the kinetic energy will disperse leading to poor functional performance. ${ }^{22}$

The rotary stability movement challenges the body's ability to stabilize during a combined upper and lower extremity motion. ${ }^{22}$ Rotary stability is an asymmetrical movement and requires different movements to occur on each side of the body while stabilizing the trunk in the transverse plane. ${ }^{13}$ An increase in core stability is important for increased performance within sports. $^{32}$

Lower Quarter Y Balance Test

The Lower Quarter Y Balance Test (LQYBT) is a tool used to identify an individual's risk for injury. The LQYBT is a modification of the Star Excursion Balance Test (SEBT). The test measures dynamic balance during a single leg stance and requires strength, proprioception and 
flexibility. The SEBT has demonstrated reliable results on its ability to predict lower extremity injury in high school basketball players. ${ }^{14}$ The LQYBT has identified athletes who are at an increased risk for injury. ${ }^{14}$

Butler $^{21}$ concluded that collegiate football players with a composite score below $89 \%$ had an increased probability of injury from $37.7 \%$ to $68.1 \%$. Therefore a cutoff point of $89 \%$ composite reach on the LQYBT was established (with a sensitivity of $100 \%$ and a +LR of 3.5). ${ }^{21}$ Plisky ${ }^{33}$ assessed high school basketball players, the cut point was $94 \%$. Plisky ${ }^{33}$ found that players with an anterior reach distance difference of greater than or equal to $4 \mathrm{~cm}$ were 2.7 times more likely to sustain a lower extremity injury. Also, players with a decreased normalized composite right reach distance $(\leq 94 \%$ of their limb length) were 3 times more likely to sustain a lower extremity injury, with the risk being 6.5 times more likely in girls. ${ }^{34}$ These studies reveal that each sport/population has its own risk cut point. The LQYBT normative values have been established in healthy military members. No other values can be applied to generalize the populations. In comparison, these results may indicate the existence of sex differences in the prediction of injury risk based on dynamic balance performance when assessed by the LQYBT. ${ }^{16}$

Proprioceptive abilities have a large impact on athletic participation. Athletes rely on proprioceptive abilities and athletic skill to enhance performance and decrease risk for injury. The majority of sports activity occurs at a high intensity and rate of speed. It is essential for athletes to have highly tuned proprioceptive abilities. Proprioception also contributes to the prevention of injuries during participation of athletic events. The greatest threat to an athlete participating in sport is the risk of injury. Injuries to the lower extremity are most common and pose a great threat to the function of everyday life. An athlete with a higher degree of proprioceptive ability has a 
less chance of incurring an injury than an athlete with less proprioceptive ability. Proprioception has also been shown to be an important factor during the rehabilitation of athletic injuries.

The LQYBT showed good interrater test-retest reliability with an acceptable level of measurement error among multiple raters screening active duty service members, and a second study shows excellent reliability $(\mathrm{ICC}=0.88-0.99) .{ }^{34-35}$ Chimera $^{16}$ used the LQYTB to study 190 DI athletes (87 female, 103 male). The composite scores were compared to previous injury and no previous injury. The LQYBT classified injury status to injury history which involved the ankle, knee, hip and trunk. However, there were no significant comparisons between injuries, injury status or the asymmetries of the three reach directions. This study was able to provide a MDIC $=3.5 \%$. Test-retest reliability established by Plisky ${ }^{34}$ (ICC, 95\% CI) for maximal reach distance was excellent (0.89-0.93).

Summary

The sport of A\&T is a relatively new sport that involves gymnastic and cheerleading type maneuvers. Spotting and basing followed by falls from height are the leading cause of injury during stunting ${ }^{3-5}$ The ankle was the most frequently injured body part assessed. ${ }^{3,5-6}$ Cheerleading in comparison with other sports was shown to have a higher injury ratio for practice than in games or competition. The FMS is a screening tool developed to challenge the kinetic chain in an effort to identify compensatory motions, inefficiencies and deficits in functional movements. Reliability of the FMS has shown to be high in expert and novice raters and may be able to identify athletes that are at an increased risk for injury. Stability and mobility play a vital role in the functional movement and proper joint arthrokinematics. The LQYBT is dynamic balance tool derived from the SEBT. Proprioception and functional movement are essential to the athlete. Identification for those athletes that are at an increased risk of injury is important for the overall safety of all team members involved with each particular skill and event. 


\section{APPENDIX C}

\section{ADDITIONAL METHODS}

Table C1. Consent Information and HIPPA Form

Principal Investigator Michelle A. Sandrey, PhD, ATC

Department

College of Physical Activity and Sport Sciences

Protocol Number

1602005299

Study Title

Use of a Functional Movement Screening Tool to Determine

Injury Risk in Collegiate Acrobatics and Tumbling

Co-Investigator(s)

Sara E Spencer, ATC

\section{Contact Persons}

In the event you experience any side effects or injury related to this research, you should contact PI Dr. Michelle A. Sandrey, PhD, ATC at (304)293-0870 or at msandrey@ mail.wvu.edu or CoPI Sara Spencer, ATC at 828-729-1552 or at slspencer@mix.wvu.edu.

For information regarding your rights as a research subject, to discuss problems, concerns, or suggestions related to the research, to obtain information or offer input about the research, contact the Office of Research Compliance at (304) 293-7073.

\section{Introduction}

You have been asked to participate in this research study, which has been explained to you by Sara Spencer, ATC.. This study is being conducted by the principal investigator, Michelle A. Sandrey, PhD, ATC and Co-investigator, Sara Spencer, ATC, in the College of Physical Activity and Sport Sciences at West Virginia University. This research is being conducted to fulfill the requirements for a Thesis in Athletic Training in the College of Physical Activity and Sport Sciences at West Virginia University under the supervision of Michelle A. Sandrey, PhD, ATC.

\section{Purpose(s) of the Study}

The purpose of this study will seek to determine if compensatory movement patterns predispose acrobatics and tumbling athletes to injury, and to determine if a functional movement screen (FMS) and lower quarter Y balance test (LQYBT) could predict injury risk in the sport population.

\section{Description of Procedures}

You will be asked to fill out a questionnaire to gather demographic information (age, gender, dance history, past medical history) as well as to determine eligibility to participate in this study. This will take approximately five to ten minutes to complete. You do not have to answer all of the questions. You will have the opportunity to see the questionnaire before signing this consent form. All completed forms will be kept confidential. If you are an eligible subject, you will be asked to participate in one session of measurement. The measurement session will take approximately 25 
to 30 minutes to complete. Testing will occur on the date and time given to you by the principle investigator.

\section{Lower Quarter Y Balance Test}

The Lower Quarter Y Balance Test is a dynamic test to measure proprioception of the lower quadrant of the body. For this test you will have a demonstration period and a testing period. You will complete three trials in each direction on each leg. Before completing the test, your leg length will be measured. To perform the test, you will be standing on one leg and reaching with the other, in the anterior (forward), posteromedial (behind-right), and posterolateral (behind-left) directions. There will be approximately ten to twenty seconds of rest between trials.

\section{Functional Movement Screening}

Functional Movement Screening is an assessment of functional movement completed over seven different fundamental movements, which include dynamic stability, static stability, and mobility. For this screening you will have a demonstration period and a testing period for each section. You will complete each section for a maximum of three trials. The seven movements you will complete are the Deep Squat, Hurdle Step, Incline Lunge, Shoulder Mobility, Active Straight Leg Raise, Trunk Stability Push Up, and Rotary Stability. The deep squat will consist of holding a dowel overhead and attempting to squat parallel while keeping heels on the ground. The hurdle step will include holding a dowel behind the head resting on the shoulders. The participant will then step over the hurdle touching the heel to the ground and then returning the heel to the start position. The inline lunge will include holding the dowel in line with the spine. While maintaining contact in an upright position the participant will lunge forward, touching the knee to the ground. Shoulder mobility will consist of putting one hand overhead and touching the opposite hand that will be touching the back. The shoulder clearing test will include touching the right hand to the left shoulder without pain and touching the left hand to the right arm without pain. The active straight leg raise will consist of the participant in a supine position. While raising the leg, the opposite leg and back must remain in contact with the ground. The trunk stability push-up will involve laying prone with the hands in line with the chin. The spinal extension clearing test will be performed in a prone position. The participant will place hands under the shoulders and then press the chest off the ground surface trying to extend the elbows. Rotary stability will be tested in the quadruped position (hands and knees). The arm and same leg will be extended. Without touching the ground the elbow must touch the knee before returning to the start position. The spinal flexion clearing test is pain provocative. It includes starting in the quadruped position and then sitting back on the heels while extending the arms out as far as possible. There will be approximately ten to twenty seconds of rest between trials.

\section{Discomforts}

There are no known risks involved in participating in this research study. If at any point during the testing procedures you begin to feel any pain or discomfort, please indicate this to the present investigator. If this occurs the measurement will be suspended immediately and may be rescheduled to a later date once the pain is resolved. If you require additional evaluation, treatment will be rendered by Sara Spencer, ATC. Referral will be your own expense. 


\section{Alternatives}

You do not need to participate in this study. You may withdraw at any time with no penalty.

\section{Benefits}

You may not receive any direct benefit from this study. However this study procedures and results may help aid in other research. It could help determine a testing measure for athletic trainers to determine balance, stability, and functional movement in an A\&T population. The information gained through this study may eventually benefit others.

\section{Financial Considerations}

There will be no payments made for participation in this study. There is no cost to participants in this study.

\section{Confidentiality}

Any information about you that is obtained as a result for your participation in this research will be kept as confidential as legally possible. Your research records and test results, just like hospital records, may be subpoenaed by court order or may be inspected by the study sponsor or federal regulatory authorities without your additional consent. In any publications that result from this research, neither your name nor any information from which you might be identified will be published.

You will be randomly assigned a four digit ID number the day of data collection, which will be used to match demographic questionnaires, FMS and Y-balance test results. This will allow the investigators to maintain confidentiality by not using your name during the data collection. Also, all documents, forms and score sheets will be kept in a locked file cabinet that can only be accessed by investigators.

\section{HIPAA}

We know that information about you and your health is private. We are dedicated to protecting the privacy of that information. Because of this promise, we must get your written authorization (permission) before we may use or disclose your protected health information or share it with others for research purposes. This form gives that permission. It also helps us make sure that you are correctly told how this information will be used or disclosed. Please read the information below carefully before signing this form. Please ask any questions you may have about this form or its uses. You can decide to sign or not to sign this authorization form. However, if you choose not to sign this authorization form, you will not be able to take part in the research study.

USE AND DISCLOSURE COVERED BY THIS AUTHORIZATION. DO NOT SIGN A BLANK FORM. You or your authorized representative should thoroughly read the information below before signing this form. This form will authorize the following person(s), class (es) of 
persons, and/or organization(s) to disclose, use, and receive the information: WVU, Michelle A. Sandrey, PhD, ATC, Sara Spencer, ATC. The research site(s) carrying out this study includes Fairmont State University. If, during the course of the research, the institution listed above merges with, or is purchased by, another company or institution, this authorization to use or disclose protected health information in the research will extend to the successor, company, or institution. A self-reported injury history questionnaire that includes information on height, weight, past athletic history, past medical history of any upper extremity, lower extremity, and spinal injury will be included in this study.

SPECIFIC UNDERTANDINGS. By signing this research authorization form, you give permission for the use and/or disclosure of your protected health information described above. The purpose for the uses and disclosures you are authorizing us to carry out the research study explained to you during the informed consent process. It is also to ensure that the information relating to the research is available to all parties who may need it for research purposes. Your protected health information may be used as necessary for you research related treatment. This information may be redisclosed or used for other purposes if a recipient described in this form is not required by law to protect the privacy of the information. You have a right to refuse to sign this authorization if you do not sign this form. If you sign this authorization, you will have the right to cancel at any time, except to the extent that WVU has already taken action based upon your authorization or needs information to complete analysis and reports of data for this research study. This authorization will expire six months from today unless you cancel this sooner. To cancel this authorization, please write to the Principal Investigator, Michelle A. Sandrey, PhD, ATC at: West Virginia University, PO Box 6116, Morgantown, WV 26506. If you cancel this authorization, any information that was collected already for this study cannot be withdrawn. You will NOT be allowed to see or copy the information described on this form as long as the research is in progress, but you have a right to see and copy the information upon completion of the research in accordance with hospital policies. You have a right to receive a copy of this form after you have signed it.

In any publications that result from this research, neither your name nor any information from which you might be identified will be published without your consent.

\section{Voluntary Participation}

Participation in this study is voluntary. You may refuse to participate in this study. You may withdraw from this study at any time. Refusal to participate or withdrawal will not affect your future care, or your class standing or grades, as appropriate and will involve no penalty to you or your position as a dance major. In the event new information becomes available that may affect your willingness to allow you to participate in this study, this information will be given to you so that you can make an informed decision about whether or not to continue your participation. You have been given the opportunity to ask questions about the research, and have received answers concerning areas you did not understand. 
I willingly consent to participate in this research.

\section{Signatures}

Signature of Subject

\begin{tabular}{lll}
\hline Printed Name & Date & Time
\end{tabular}

The participant has had the opportunity to have questions addressed. The participant willingly agrees to be in the study.

Signature of Investigator or Co-Investigator

\begin{tabular}{llc}
\hline Printed Name & Date
\end{tabular}


Table C2. Injury Self-Report Questionnaire

Injury Self-Report Questionnaire

Subject Number

Age:

Height: Weight:

Year in School: (circle one) Freshman / Sophomore / Junior / Senior / Grad

Previous Sport: (circle one) Gymnastics / Cheerleading / Other

How long did you compete?

Highest Level Competed?

Primary Position: (circle one) Top / Base / Middle

Highest tumbling skill you can perform at this time:

(Ex:_Back Tuck, Full, 1 1⁄2, Arabian, Layout, Whip...etc.)

Highest tumbling series you can perform at this time:

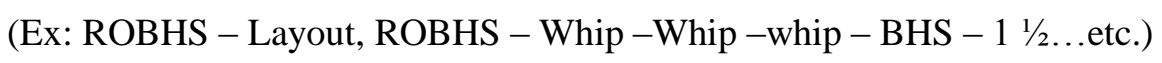

Have you had a history of lower body injury in the past six months that has required medical intervention?

1. Body Part Injured:

What happened?

Diagnosis:

Days Missed of Sport:

Days Modified:

Is this an ongoing injury? If so, please explain why.

2. Body Part Injured:

What happened?

Diagnosis:

Days Missed of Sport:

Days Modified:

Is this an ongoing injury? If so, please explain why. 
Have you had a history of upper body injury in the past six months that has required medical intervention?

1. Body Part Injured:

What happened?

Diagnosis:

Days Missed of Sport:

Days Modified:

Is this an ongoing injury? If so, please explain why.

2. Body Part Injured:

What happened?

Diagnosis:

Days Missed of Sport:

Days Modified:

Is this an ongoing injury? If so, please explain why.

Have you had a history of abdominal or back injury in the past six months that has required medical intervention?

1. Body Part Injured:

What happened?

Diagnosis:

Days Missed of Sport:

Days Modified:

Is this an ongoing injury? If so, please explain why. 
Please list all other injuries sustained during sport within the last three years.

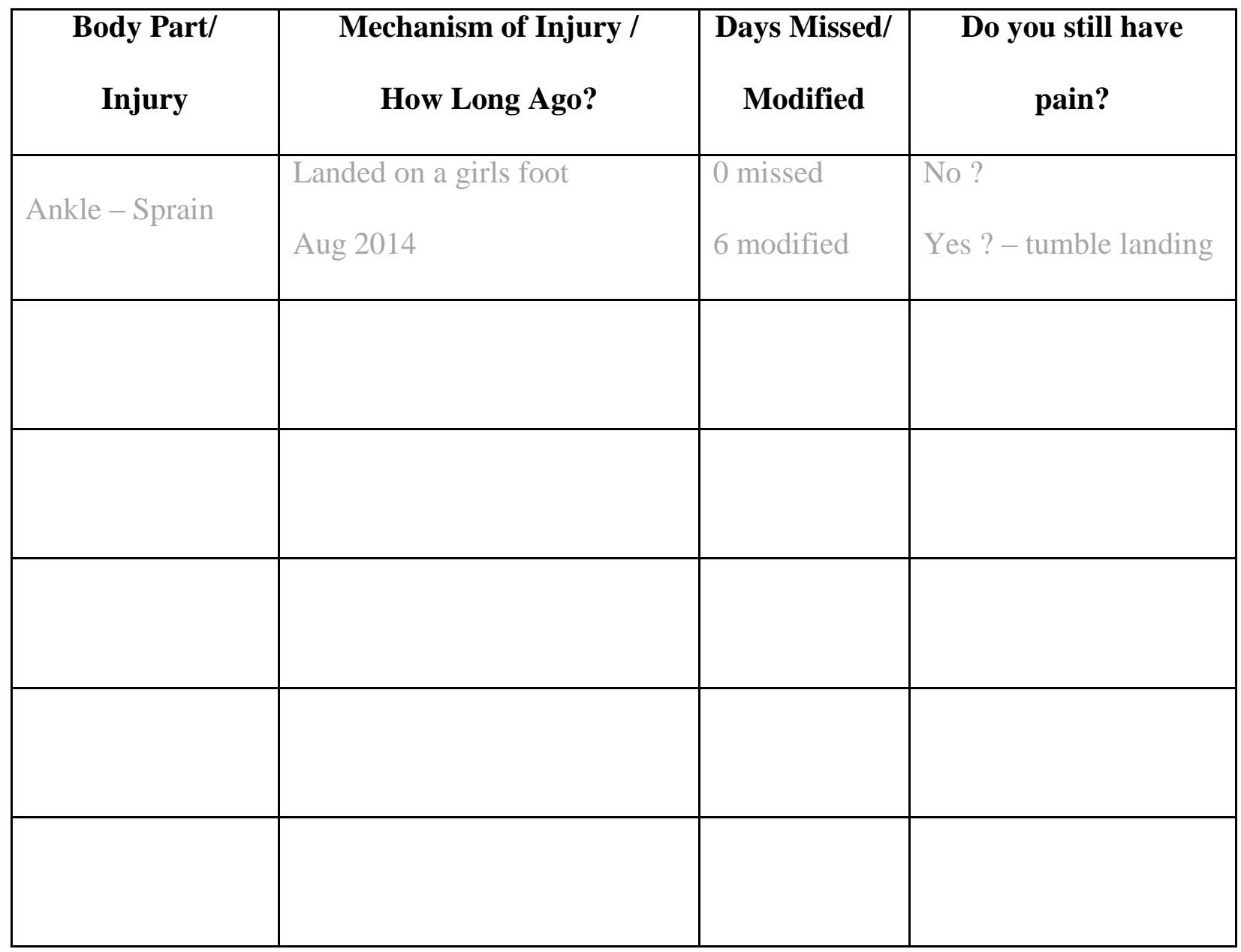


Table C3. Verbal Instructions for Functional Movement Screen ${ }^{36}$

VERBAL INSTRUCTIONS FOR

\section{THE FUNCTIONAL MOVEMENT SCREEN}

The following is a script to use while administering the FMS. For consistency throughout all screens, this script should be used during each screen. The bold words represent what you should say to the client.

Please let me know if there is any pain while performing any of the following movements.

\section{DEEP SQUAT}

EQUIPMENT NEEDED: DOWEL, 2X6

INSTRUCTIONS

- Stand tall with your feet approximately shoulder width apart and toes pointing forward.

- Grasp the dowel in both hands and place it horizontally on top of your head so your shoulders and elbows are at 90 degrees.

- Press the dowel so that it is directly above your head.

- While maintaining an upright torso, and keeping your heels and the dowel in position, descend as deep as possible.

- Hold the descended position for a count of one, then return to the starting position.

- Do you understand the instructions?

Score the movement.

The client can perform the move up to three times total if necessary. If a score of three is not achieved, repeat above instructions using the 2 x 6 under the client's heels.

HURDLE STEP

EQUIPMENT NEEDED: DOWEL, HURDLE

INSTRUCTIONS

- Stand tall with your feet together and toes touching the test kit.

- Grasp the dowel with both hands and place it behind your neck and across the shoulders.

- While maintaining an upright posture, raise the right leg and step over the hurdle, making sure to raise the foot towards the shin and maintaining foot alignment with the ankle, knee and hip.

- Touch the floor with the heel and return to the starting position while maintaining foot alignment with the ankle, knee and hip.

- Do you understand these instructions?

Score the moving leg.

Repeat the test on the other side.

Repeat two times per side if necessary 


\section{INLINE LUNGE}

EQUIPMENT NEEDED: DOWEL, 2X6

\section{INSTRUCTIONS}

- Place the dowel along the spine so it touches the back of your head, your upper back and the middle of the buttocks.

- While grasping the dowel, your right hand should be against the back of your neck, and the left hand should be against your lower back.

- Step onto the $2 \times 6$ with a flat right foot and your toe on the zero mark.

- The left heel should be placed at mark. This is the tibial measurement marker.

- Both toes must be pointing forward, with feet flat.

- Maintaining an upright posture so the dowel stays in contact with your head, upper back and top of the buttocks, descend into a lunge position so the right knee touches the $2 \times 6$ behind your left heel.

- Return to the starting position.

- Do you understand these instructions?

Score the movement.

Repeat the test on the other side.

Repeat two times per side if necessary

\section{SHOULDER MOBILITY}

EQUIPMENT NEEDED: RULER

\section{INSTRUCTIONS}

- Stand tall with your feet together and arms hanging comfortably.

- Make a fist so your fingers are around your thumbs.

- In one motion, place the right fist overhead and down your back as far as possible while simultaneously taking your left fist up your back as far as possible.

- Do not "creep" your hands closer after their initial placement.

- Do you understand these instructions?

Measure the distance between the two closest points of each fist.

Score the movement.

Repeat the test on the other side. 


\section{ACTIVE SCAPULAR STABILITY (SHOULDER CLEARING)}

\section{INSTRUCTIONS}

- Stand tall with your feet together and arms hanging comfortably.

- Place your right palm on the front of your left shoulder.

- While maintaining palm placement, raise your right elbow as high as possible.

- Do you feel any pain?

Repeat the test on the other side.

\section{ACTIVE STRAIGHT-LEG RAISE}

EQUIPMENT NEEDED: RULER, DOWEL, 2X6

\section{INSTRUCTIONS}

- Lay flat with the back of your knees against the $2 \times 6$ with your toes pointing up.

- Place both arms next to your body with the palms facing up.

- Pull the toes of your right foot toward your shin.

- With the right leg remaining straight and the back of your left knee maintaining contact with the $2 \times 6$, raise your right foot as high as possible.

- Do you understand these instructions?

Score the movement.

Repeat the test on the other side.

\section{TRUNK STABILITY PUSH-UP}

EQUIPMENT NEEDED: NONE

\section{INSTRUCTIONS}

- Lie face down with your arms extended overhead and your hands shoulder width apart.

- Pull your thumbs down in line with the (forehead for men, chin for women).

- With your legs together, pull your toes toward the shins and lift your knees and elbows off the ground.

- While maintaining a rigid torso, push your body as one unit into a pushup position.

- Do you understand these instructions?

Score the movement.

Repeat two times if necessary.

Repeat the instructions with appropriate hand placement if necessary 


\section{SPINAL EXTENSION CLEARING}

\section{INSTRUCTIONS}

- While lying on your stomach, place your hands, palms down, under your shoulders.

- With no lower body movement, press your chest off the surface as much as possible by straightening your elbows.

- Do you understand these instructions?

- Do you feel any pain?

\section{ROTARY STABILITY}

EQUIPMENT NEEDED: 2X6

\section{INSTRUCTIONS}

- Get on your hands and knees over the $2 \times 6$ so your hands are under your shoulders and your knees are under your hips.

- The thumbs, knees and toes must contact the sides of the $2 \times 6$, and the toes must be pulled toward the shins.

- At the same time, reach your right hand forward and right leg backward, like you are flying.

- Then without touching down, touch your right elbow to your right knee directly over the $2 \times 6$.

- Return to the extended position.

- Return to the start position.

- Do you understand these instructions?

Score the movement.

Repeat the test on the other side.

If necessary, instruct the client to use a diagonal pattern of right arm and left leg.

Repeat the diagonal pattern with left arm and right leg.

Score the movement.

\section{SPINAL FLEXION CLEARING}

\section{INSTRUCTIONS}

- Get on all fours, and rock your hips toward your heels.

- Lower your chest to your knees, and reach your hands in front of your body as far as possible.

- Do you understand these instructions?

- Do you feel any pain? 


\section{FUNCTIONAL MOVEMENT SCREEN}
Score
Criteria
Illustration

\section{Deep Squat}

3

2

1

0

\section{Hurdle Step (test right and left)*}

3

0

- Pain during test

- Loss of balance noted

- Upper torso is parallel with tibia or toward vertical

- Femur below horizontal

- Knees are aligned over feet

- Dowel aligned over feet

Performed with heels on 2x6in board

- Upper torso is parallel with tibia or toward vertical

- Femur below horizontal

- Knees are aligned over feet

- Dowel aligned over feet

Performed with heels on $2 \times 6$ in board

- If any of the 4 criteria are not met when the squat is performed with heels on $2 \times 6$ in board, the score is a 1
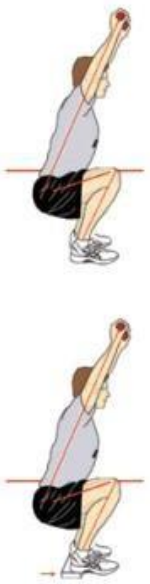

as leg is lifted over hurdle

- Hips, knees, and ankles remain aligned in the sagittal plane

- Minimal to no movement is noted in lumbar spine

- Dowel and hurdle remain parallel

- Alignment is lost between hips, knees and ankles

- Movement is noted in lumbar spine

- Dowel and hurdle do not remain parallel

- Contact between foot and hurdle

- Pain during test 


\section{In-line Lunge (test right and left)*}

3

2

1

0

\section{Active Straight Leg Raise (test right and left)*}

3

2

1

0 opposite lower extremity rotate), toes remain pointed up extremity while other criteria are met other criteria are met
- Knee touches board behind heel

- Dowel and feet remain in sagittal plane

- Dowel contacts remain (head, thoracic spine, sacrum)

- Dowel remains vertical, no torso movement noted

- Knee does not touch behind heel

- Dowel and feet do not remain in sagittal plane

- Dowel contacts so not remain

- Dowel remains vertical

- Movement noted in torso

- Loss of balance

- Inability to achieve start position

- Inability to touch knee to board

- Pain during test

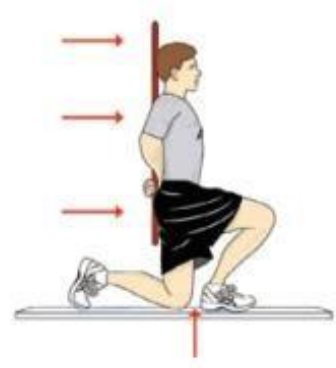

- Malleolus of tested lower extremity located in the region between mid-thigh and anterior superior iliac spine of

- Opposite hip remains neutral ( hip does not externally

- Opposite knee remains in contact with board

- Malleolus of tested lower extremity located in the region between mid-thigh and knee joint line of opposite lower

- Malleolus of tested lower extremity located in the region

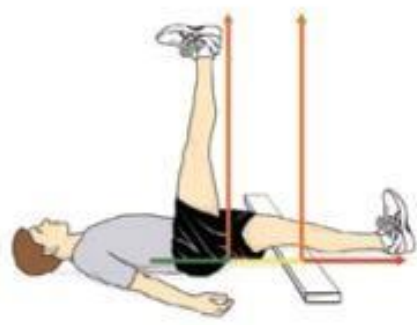
below knee joint line of opposite lower extremity, while

- Pain during test 


\section{Shoulder Mobility (test right and left)*}

3

2

1

0

- Fists are within 1 hand length

- Fists are within 1.5 hand lengths

- Fists are not within 1.5 had lengths

- Pain during test

Shoulder Mobilitv Clearing Test

If pain is noted as elbow is lifted, shoulder mobility is scored as 0

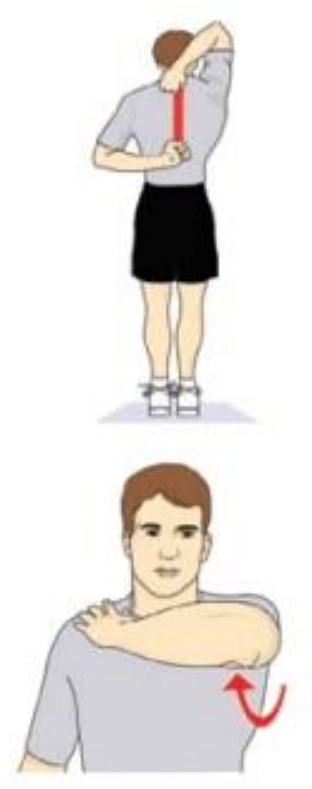

\section{Trunk Stability Push-Up}

3

2

1

0

\section{Extension Clearing Test}

- Perform 1 rep: thumbs are aligned with forehead for males and chin for females

- Body is lifted as 1 unit (no sag in lumbar spine)

- Perform 1 rep: thumbs are aligned with chin for males and clavicle for females

- Unable to perform 1 repetition with thumbs aligned with chin for males and clavicle for females

- Pain during test
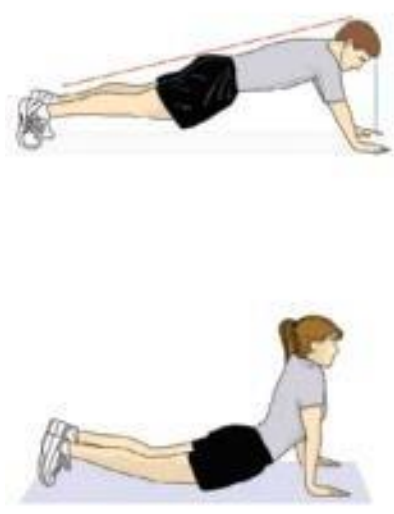

If pain is noted during a prone press-up, push-up is scored as 0 


\section{Quadruped Rotary Stability (test right and left)*}

3

2

1

0

Flexion Clearing Test

- 1 unilateral repetition (lift arm and leg from same side)

- Keep spine parallel to board

- Knee and elbow touch in line over the board and then return to the start position

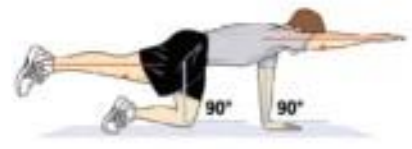

- 1 unilateral repetition (lift arm and leg from opposite side)

- Keep spine parallel to board

- Knee and elbow touch in line over the board and then return to the start position

- Inability to perform diagonal repetition

- Pain during test

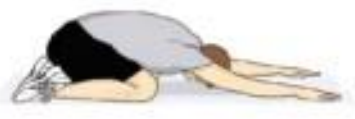

*Tests that are scored for both right and left sides, the lower score is used when calculating FMS composite score. 
Table C5. Functional Movement Screen Scoring Sheet

\section{THE FUNCTIONAL MOVEMENT SCREEN SCORING SHEET}

SUBJECT NUMBER

DATE

HAND/LEG DOMINANCE

SCHOOL FAIRMONT STATE UNIVERSITY

HEIGHT

WEIGHT

AGE

GENDER FEMALE

SPORT ACRO \& TUMBLING POSITION

\begin{tabular}{|c|c|c|c|c|}
\hline \multicolumn{2}{|l|}{ TEST } & RAW SCORE & \multirow[t]{2}{*}{ FINAL SCORE } & \multirow[t]{2}{*}{ COMMENTS } \\
\hline \multicolumn{2}{|l|}{ DEEP SQUAT } & & & \\
\hline \multirow{2}{*}{ HURDLE STEP } & $\mathbf{L}$ & & & \\
\hline & $\mathbf{R}$ & & & \\
\hline \multirow{2}{*}{ INLINE LUNGE } & $\mathbf{L}$ & & & \\
\hline & $\mathbf{R}$ & & & \\
\hline \multirow{2}{*}{ SHOULDER MOBILITY } & $\mathbf{L}$ & & & \\
\hline & $\mathbf{R}$ & & & \\
\hline \multirow{2}{*}{ IMPINGEMENT CLEARING TEST } & $\mathbf{L}$ & & & \\
\hline & $\mathbf{R}$ & & & \\
\hline \multirow{2}{*}{ ACTIVE STRAIGHT LEG RAISE } & $\mathbf{L}$ & & & \\
\hline & $\mathbf{R}$ & & & \\
\hline \multicolumn{5}{|l|}{ TRUNK STABILITY PUSH UP } \\
\hline \multicolumn{2}{|l|}{ PRESS UP CLEARING TEST } & & & \\
\hline \multirow{2}{*}{ ROTARY STABILITY } & $\mathbf{L}$ & & & \\
\hline & $\mathbf{R}$ & & & \\
\hline \multicolumn{2}{|c|}{ POSTERIOR RoCKING ClEARING TEST } & & & \\
\hline TOTAL & & & & \\
\hline
\end{tabular}

RAW SCORE: This score is used to denote right and left side scoring. The right and left sides are scored in five of the seven tests and both are documented in this space.

FINAL SCORE: This score is used to denote the overall score for the test. The lowest score for the raw score (each side) is carried over to give a final score for the test. A person who scores a three on the right and a two on the left would receive a final score of 2 . The final score is then summarized and used as a total score. 


\section{LQ-YBT Testing Instructions}

Take a measurement from the Anterior Superior Iliac Spine to the Inferior Medial Malleolus.

Record in centimeters.

Scores do not count if errors are present. Three scores in each direction shall be documented.

Errors Include

- Touching the reach foot down outside of the taped lines

- Touching the reach foot to the ground for balance

- Allow the stance heel to lose contact with the floor

Instruct subject to remove shoes.

Place the right foot behind the line.

You will get up to 3 practice trials in each direction.

A total of 3 scores will be recorded.

Reach the left foot forward as far as possible without error.

Reach back and to the left without error.

Reach back and to the right without error.

Place the left foot behind the line.

You will get up to 3 practice trials in each direction.

A total of 3 scores will be recorded.

Reach the right foot forward as far as possible without error.

Reach back and to the right without error.

Reach back and to the left without error.

A total of three scores will be tallied for each direction on the right and left legs.

The longest scored distance will be taken as the final score.

A difference in right and left scores will be calculated.

A composite score will be calculated to give a percentage.

The percentages will provide a cut point to identify those at risk for injury. 
Table C7. Lower Quarter Y Balance Test Scoring Sheet ${ }^{35}$

\section{LOWER QUARTER Y BALANCE TEST SCORING SHEET}

DATE

RIGHT LIMB LENGTH

LEFT LIMB LENGTH

\begin{tabular}{|l|l|l|l|l|}
\hline \multicolumn{1}{|c|}{ TEST } & LEFT & RIGHT & DIFFERENTIAL & COMMENTS \\
\hline ANTERIOR & & & & \\
\hline POSTERIOR-MEDIAL & & & & \\
\hline POSTERIOR-LATERAL & & & & \\
\hline
\end{tabular}

**DIFFERENCE SHOULD BE LESS THAN 4CM FOR RETURN TO SPORT AND PRE-PARTICIPATION SCREENING**

COMPOSITE SCORE $=\underline{(\text { Anterior }+ \text { Posterior Medial }+ \text { Posterior Lateral })}$ ( 3x Leg Length)

x 100

COMPOSITE SCORE

\begin{tabular}{|c|l|}
\hline RIGHT & \\
\hline LEFT & \\
\hline
\end{tabular}




\section{APPENDIX D}

\section{ADDITNIONAL RESULTS}

Table D1. Summary of Demographic Data

\begin{tabular}{llllll}
\hline & \# Subjects (n) & Age & Ht $(\mathrm{cm})$ & Wt $(\mathrm{kg})$ & $\begin{array}{l}\text { Years of } \\
\text { Competition }\end{array}$ \\
\hline $\begin{array}{lllll}\text { All } \\
\text { Subjects }\end{array}$ & 22 & $19.25 \pm 0.91$ & $161.97 \pm 7.03$ & $62.53 \pm 8.71$ & $9.18 \pm 3.63$ \\
Top & 6 & $19.5 \pm 0.57$ & $154.07 \pm 6.35$ & $53.14 \pm 5.28$ & $10.16 \pm 3.81$ \\
Base & 15 & $19.13 \pm 0.99$ & $165.25 \pm 4.64$ & $66.52 \pm 6.93$ & $9.13 \pm 3.5$ \\
Middle & 1 & 20 & 160.02 & 58.96 & 4 \\
\hline
\end{tabular}

Table D2. Summary of FMS Score and LQYBT Scores

\begin{tabular}{llll}
\hline & FMS & LQYBT $(\mathrm{L})$ & LQYBT $(\mathrm{R})$ \\
\hline Total $(\mathrm{n}=22)$ & $15.9 \pm 1.87$ & $99.24 \pm 12.01$ & $98.36 \pm 11.63$ \\
Top $(\mathrm{n}=6)$ & $16.5 \pm 1.87$ & $105.36 \pm 18.90$ & $103.54 \pm 17.56$ \\
Base $(\mathrm{n}=15)$ & $15.8 \pm 1.80$ & $97.24 \pm 8.08$ & $96.47 \pm 8.77$ \\
Middle $(\mathrm{n}=1)$ & 13 & 92.50 & 95.60 \\
\hline
\end{tabular}


Table D3. Six Month Injury Self-Report Data

\begin{tabular}{llll} 
MOI & Injury & \multicolumn{1}{c}{ Type } & N \\
\hline Tumbling & Ankle & Sprain & 3 \\
& & Strain & 1 \\
& Heel & Contusion & 1 \\
& Achilles & Strain & 1 \\
& Knee & Sprain & 1 \\
Ouad & Strain & 1 \\
Overuse & Calf/Lower Leg & Stress & 1 \\
& Spine & Disc & 2 \\
Stunting & Knee & Sprain & 1 \\
& Sternum & Contusion & 1 \\
& Wrist & Tendinopathy & 2 \\
& Thumb & Sprain & 1 \\
Vault & Finger & Fracture & 1 \\
Non-Athletic Related & Wrist & Fracture & 1 \\
Previous Injury & Ankle & Sprain & 1 \\
& Elbow & Surgery & 1 \\
\hline
\end{tabular}


Table D4. Self-Reported Injuries Over 3 Year Span

\begin{tabular}{|c|c|c|c|}
\hline Mechanism & Injury & Type & $\mathrm{N}$ \\
\hline \multirow[t]{15}{*}{ Tumbling } & \multirow[t]{3}{*}{ Ankle } & Sprain & 12 \\
\hline & & Strain & 1 \\
\hline & & Fracture & 1 \\
\hline & Heel & Contusion & 1 \\
\hline & Achilles & Strain & 1 \\
\hline & Knee & Sprain & 4 \\
\hline & Quad & Strain & 1 \\
\hline & Foot & Fracture & 1 \\
\hline & Calf/Lower Leg & Stress & 1 \\
\hline & Knee & Tendinopathy & 1 \\
\hline & ITB & Tightness & 2 \\
\hline & \multirow[t]{3}{*}{ Spine } & NOS & 1 \\
\hline & & Sprain & 1 \\
\hline & & Disc & 2 \\
\hline & Wrist & Fracture & 1 \\
\hline Landing on another Athlete & Ankle & Sprain & 3 \\
\hline \multirow[t]{5}{*}{ Stunting } & Knee & Sprain & 1 \\
\hline & Sternum & Contusion & 1 \\
\hline & Wrist & Tendinopathy & 3 \\
\hline & Thumb & Sprain & 1 \\
\hline & Finger & Fracture & 1 \\
\hline Conditioning & Quad & Strain & 1 \\
\hline Vault & Wrist & Fracture & 1 \\
\hline Bars & Shoulder & Sprain & 1 \\
\hline \multirow[t]{2}{*}{ Non-Athletic Related } & Ankle & Sprain & 1 \\
\hline & Wrist & Sprain & 1 \\
\hline \multirow[t]{4}{*}{ HS Sport } & Ankle & Contusion & 1 \\
\hline & Hamstring & Strain & 1 \\
\hline & Spine & Fracture & 1 \\
\hline & Shoulder & Tendinopathy & 1 \\
\hline Previous Injury & Elbow & Surgery & 1 \\
\hline
\end{tabular}




\section{APPENDIX E \\ RECOMMENDATION FOR FUTURE RESEARCH}

1. Injury surveillance over one full season (fall and spring) to allow for a more thorough injury assessment, time-loss, reoccurrence and return to play variables when considering the $14 \mathrm{pt}$ cut.

2. Pre and post-test testing would give the clinician/investigator retrospective and objective data to help provide a basis of improvement in deficits of functional movements.

3. Single leg measures and analysis could provide a better understanding of deficits in a unilateral position that may not be seen during double leg test. Single leg measures can be used to compare deficits and provide the clinician with information to create a prevention program.

4. Reevaluate the cut-off value by researching more subjects within the population to determine if 14 is the appropriate cut-off 


\section{ADDITIONAL REFERENCES}

1. Cook EG, Burton L, Hoogenboom BJ. Pre-participation screening: The use of fundamental movements as an assessment of function-Part 2. N AM J Sports Phys Ther.

2006;1(3):132-139.

2. Shultz MR, Marshall SW, Yang J, Mueller FO, Weaver NL, Bowling JM. A prospective cohort study of injury incidence and risk factors in North Carolina high school competitive cheerleaders. Am J Sports Med. 2004;32(2):396-405.

3. Mueller FO, Cantu RC. National Center for Catastrophic Sports Injury Research: twentyfifth annual report, fall 1982-spring 2007.

4. MaCarther C, Hu X, Wesson DE, Parkin PC. Risk factors for severe injuries associated with falls from playground equipment. Accid Anal Prev. 2000;32(3):377382.

5. American Society for Testing and Materials. ATSM F1292-04 Standard Specification for Impact Attenuation of Surfacing Materials Within the Use of Zone of Playground Equipment. West Conshohocken, PA: American Society for Testing Materaials. 2004.

6. Teyhen DS, Shaffer SW, Lorenson CL, Halfpap JP, Donofry DF, Walker MJ, Dugan JL, Childs JD. The functional movement screen: a reliability study. J Ortho Sports Phys Ther. 2012;42(6):530-540.

7. Okada T, Huxel, KC, esser, TW. Relationship between core stability, functional movement, and performance. J Strength Cond Res. 2010: 1-10.

8. Herman SL, Smith DT.. Four-week dynamic stretching warm-up intervention elicits longer-term performance benefits. J Strength Cond Res. 2008;22(4):1286 -1297 .

9. Sell TC, Tsai Y, Smoliga JM, Myers JB, Lephart, SM. Strength, flexibility, and balance characteristics of highly proficient golfers. J Strength Cond Res. 2007;21(4):1166 - 1171.

10. Paterno, M.V., Myer, G.D., Ford, G.D., \& Hewett, T.E. (2004). Neuromuscular training improves single-limb stability in young female athletes. J Ortho Sports Phys Ther, 34(6),305-316.

11. King MA. Functional stability for the upper quarter. Athl Ther Today. 2000;5(2)17-21.

12. Abt JP, Smoliga JM, Brick MJ, Jolly JT, Lephart LM, Fu FH. Relationship between cycling mechanics and core stability. J Strength Cond Res. 2007;21(4):1300-1304. 
13. Plisky PJ, Rauh MJ, Kaminski TW, Underwood FB. Star excursion balance test as a predictor of lower extremity injury in high school basketball players. J Orthop Sports Phys Ther. 2006;36(12):911-9.

14. Plisky PJ, Gorman PP, Butler RJ, Kiesel KB, Underwood FB, Elkins B. The reliability of an instrumented device for measuring components of the star excursion balance test. N Am J Sports Phys Ther. 2009 May;4(2):92-9.

15. Shaffer SW, Teyhen DS, Lorenson CL, Warren RL, Koreerat CM, Straseske CA, Childs JD. Y-Balance Test: a reliability study involving multiple raters. Mil Med. 2013;178(11):1264-70.

16. Functional Movement. Available at www.functionalmovement.com. Accessed November 1, 2015.

17. Y Balance Test. Available at www.ybalancetest.com. Accessed November 1, 2015. 